\title{
2 The assessment of ceramic and mixed recycled aggregates 3 for high strength and low shrinkage concretes
}

\author{
Miren Etxeberria (i) - Andreu Gonzalez-Corominas
}

\begin{abstract}
Very few studies on recycled aggregate concretes (RC) have been extended to the use of recycled ceramic and mixed aggregates in relation with high strength concretes. In the main they concentrate only on the analysis of the physical and mechanical properties. This study deals with the investigation of the influence that different percentages (up to $30 \%$ substitution for natural aggregates) of high porous ceramic and mixed recycled aggregates have over the plastic, autogenous and drying shrinkage of the concretes. The physical and mechanical properties as well as the chloride resistance were also determine in order to assess the viability of the use of ceramic and mixed recycled aggregates in high strength concretes. The results revealed that the employment of highly porous recycled aggregates reduced the plastic and autogenous shrinkage values of the concrete with respect to those obtained by conventional concrete (CC). Although the total drying shrinkage of the recycled concrete proved to be $25 \%$ higher than that of the CC concrete, the CC concrete had in fact a higher shrinkage value than that of the RC from 7 to 150 days of drying. It can be concluded that the RC concrete produced employing up to $30 \%$ of fine ceramic aggregates (FCA, with $12 \%$ of absorption capacity) achieved the lowest shrinkage values and
\end{abstract}

A1 M. Etxeberria $(\bowtie) \cdot$ A. Gonzalez-Corominas

A2 Department of Civil and Environmental Engineering,

A3 Polytechnic University of Catalonia, Jordi Girona, 1-3 B1

A4 Building, Barcelona 08034, Spain

A5 e-mail: miren.etxeberria@upc.edu higher mechanical and chloride ion resistance. In addition, the concrete produced with low percentage $(10-15 \%)$ of recycled mixed aggregates also had similar properties to conventional concrete.

Keywords Recycled ceramic aggregates - Mixed aggregates $\cdot$ Shrinkage $\cdot$ High strength recycled concrete $\cdot$ Physical-mechanical properties

\section{Introduction}

The use of recycled aggregates as replacement for natural aggregates in concretes, especially those exclusively sourced from recycled concrete waste [1-4] has been intensively analysed as a means of providing a preventive environmental method with respect to the reduction of construction and demolition waste. In contrast, the study of the utilization of ceramic or mixed recycled aggregates is relatively new.

In Southern Europe there has been a long tradition of using ceramic materials, such as tiles, bricks and blocks, in the construction industry. Ceramic waste can be found both in the production of ceramic materials and in the demolition of existing buildings [5]. Ceramic waste represents an important amount of the construction and demolition waste that reaches recycling and treatment plants.

\begin{tabular}{|l|lll|}
\hline & Journal : Medium 11527 & Dispatch : 24-9-2018 & Pages : 21 \\
Article No. : $\mathbf{1 2 4 4}$ & $\square$ LE & $\square$ TYPESET \\
MS Code : MAAS-D-17-01211 & $\checkmark \mathrm{CP}$ & $\checkmark$ DISK \\
\hline
\end{tabular}


According to Deloitte [6] excluding soil and dredging spoil, the 28 MS generated around 350 Mtonnes of CDW in 2012 of which 28 million tons were generated by Spain. According to Deloitte [6] Spain is among the top 5 countries with the highest value of generated CDW related to the turnover of the construction sector (in $€$ Million), with a value of approximately 230 Tonnes per million Euros, resulting in Spain being a very inefficient country in this respect. Although Spain achieves the 70\% target for re-use, recycling and recovery defined by the European Union [7] when backfilling is taking into account.

It falls short of European Union objectives when backfilling is eliminated and only achieving a recovery rate of $30 \%$. One must be reminded that backfilling is contrary to the primary objective of high quality recycling. Spanish government Ministry of Agriculture, Food and the Environment published the State Waste Framework Plan (PEMAR) 2016-2022 [8] in which it stated two important objectives. Firstly, the need for an increase in the use of qualitative recycled materials and secondly the need to include environmental costs within the costing of natural aggregates in order to make recycled aggregates more competitively priced. Barcelona has several recycling facilities of CDW guaranteeing the supplying of recycled aggregates, thus avoiding long transportation and hence making it economically viable.

Although the Japanese standards JIS A 5021-23 allow for the use of fine recycled aggregates [3], their use in concrete and mortar production is not permitted in most countries [9-12]. Most of the studies dealing with the employment of the use of ceramic and mixed recycled aggregates have been focused on low-grade concretes or standard-strength concretes [12-14], and very few have dealt with the production of highstrength concretes [15-18].

The use of recycled mixed aggregates (RMA) is limited due to the high variability of their composition. Moreover, the high water absorption capacity of recycled ceramic aggregates (RCA), with $100 \%$ ceramic material content, and RMA aggregates has also limited their use in construction [19]. De Brito et al. [5] listed the water absorption disparity between ceramic and natural aggregates as one of the main difficulties encountered with regards to the use of ceramic aggregates in the production of concrete, resulting in decreases on strength, workability and durability. Nevertheless, the pre-soaking of highly porous recycled aggregates is an extensively accepted method of minimizing these consequences $[4,5,15]$ as well as also even improving the mechanical properties of the concretes produced.

A comparative study between the results obtained from conventional concrete and recycled aggregate concretes produced with ceramic aggregates has proved the latter to exhibit superior mechanical behaviour [18, 20]. It was also observed that the microstructure that existed in the interfacial transition zone (ITZ) between the recycled ceramic aggregate and the paste was more compact than in the case of natural aggregate and paste. $50 \%$ of fine ceramic aggregates was established as the optimum replacement ratio in order to maintain similar workability and compressive strength to those of conventional concrete $[19,21,22]$. The percentage reduced to $25-30 \%$ when mixed recycled aggregates were employed in concrete production [17, 18]. According to certain researchers [18, 23-25], all mixes containing crushed ceramic bricks showed a high resistance to chloride penetration and durability, confirming the positive impact of using these aggregates. The mentioned improvement occurring via the reduction of the internal stress that could take place as a result of water scarcity within the high performance concrete. Those highly porous aggregates acting similarly to lightweight aggregates [15].

Fujiwara [26] determined that the concretes produced employing lightweight aggregates had a lower shrinkage strain than that of conventional concrete. Saturated lightweight aggregates have been used to provide internal curing for the concrete and mitigate autogenous shrinkage which leads on to greater selfdesiccation and higher internal stress, especially within the first $24 \mathrm{~h}$ of curing [27-32]. Suzuki et al. [15] also determined that the same properties exposed existed in high water absorption recycled aggregates.

Although the ultimate shrinkage strain of concretes is contributed to by autogenous shrinkage, plastic and drying shrinkage $[33,34]$, the majority of the studies on recycled aggregates only deal with the analysis of the drying shrinkage. In addition, the majority of recent research work dealing with the assessing of the shrinkage strain of recycled aggregate concrete has been carried out via the employment of recycled concrete aggregates [35-39]. According to the latest research work, Sadati and Khayat [35] concluded that although concrete produced with $50 \%$ recycled

\begin{tabular}{|l|lll|}
\hline & Journal : Medium 11527 & Dispatch : 24-9-2018 & Pages : 21 \\
Article No. : $\mathbf{1 2 4 4}$ & $\square$ LE & $\square$ TYPESET \\
& MS Code : MAAS-D-17-01211 & $\square_{\mathrm{CP}}$ & $\checkmark$ DISK \\
\hline
\end{tabular}


concrete aggregates suffered higher shrinkage levels than that of conventional concrete, their results showed that there was no cracking during the drying process and consequently these concretes could be considered as "low" potential for cracking. Medjigbodo et al. [37] concluded that the influence of recycled concrete aggregate content on the ultimate shrinkage was significant but also relatively low. The higher mass loss detected during the first few days was due to higher free water content but this in fact did not result in a higher drying depth.

The most recent researches on concretes employing recycled ceramic materials (bricks [15, 17] and tiles [40]) concluded that they could enhance the properties of high performance concrete with respect to internal curing, thus offering an addition value to the ceramic waste. On the basis of their research they have concluded that there was not only a high effectiveness of the ceramic aggregates in reduction and even complete elimination of autogenous shrinkage, but also on the minimizing early-age cracking in high performance concrete where a low water-to-binder ratio was used. Bui et al. [40] went on to state that the employment of $40 \%$ of roof-tile waste aggregate in the concrete mix not only reduced the volume of capillary pores but also increased the development in the compressive strength of concrete produced employing ordinary Portland cement as well as fly ash. The results proving to be significant in the early stages of curing and then gradual up to 728 days, due to the internal curing caused by saturated recycled aggregates.

Bravo et al. [41] described that although the incorporation of RMA aggregates increased the total shrinkage, generally there is no consensus on the extent of this increase. According to Bravo et al. [41] there are three different aspects which may contribute to the widespread scatter in the reported values. (1) The higher shrinkage of RC is caused by the higher porosity and lower Young's modulus of recycled aggregates; (2) The water absorbed by the recycled aggregates during mixing provides an internal curing mechanism that mitigates shrinkage caused by early age water evaporation; (3) Most studies on RC use recycled aggregates sourced from concrete produced in the laboratory, so it is more than probable that these test concretes could be classified as young concretes.

Due to the difficulty of analyzing the separate effect of incorporating recycled aggregates on each of the shrinkage processes, Silva et al. [42] analysed the total shrinkage prediction of recycled aggregate concrete. It was concluded that the recycled concrete obtained a higher shrinkage strain via the increasing of the percentages of recycled aggregates incorporated in the concrete mix. However, there is disagreement as to whether it is the recycled concrete aggregate (CA) or the recycled mixed aggregates (RMA) which causes greater shrinkage. Firstly, RMA normally has a lower elastic modulus than that of recycled concrete aggregates-CA and thus has less stiffness and capacity to control shrinkage as well as generally absorbing a greater amounts of water than recycled concrete aggregates-CA, which in turn can provide internal curing and thus prevent the concrete produced from drying too rapidly. The possible applicability of high absorption capacity aggregates, RMA and RCA in fine or coarse fraction in reducing the strain behaviour in high performance concrete, leads one to believe in the necessity for further research in this matter.

In the current study the ceramic and mixed recycled aggregates available in the city of Barcelona, which were obtained from the ceramic factory and recycling plant, were employed for concrete production. The aim of the work was to investigate the influence of the use of fine recycled ceramic aggregates (FCA) and fine and coarse recycled mixed aggregates (FMA and CMA) on the plastic, autogenous and drying shrinkage of high-strength concrete. Three replacement ratios $(10,20$ and 30\%) were selected for the fine recycled aggregates and two (15 and 30\%) were chosen for the coarse recycled aggregate in replacement of natural aggregates. Both the physical and mechanical properties, as well as the chloride resistance of the highstrength recycled aggregate concretes were included in the experimental programme in order to assess the viability of using ceramic and mixed recycled aggregates in high-strength concrete.

\section{Experimental details}

\subsection{Materials}

\subsubsection{Binder materials and admixtures}

A commercially available high strength and rapidhardening Portland cement (CEM I 52.5R), equivalent to ASTM type III Portland cement, was used in the production of all the concrete mixtures. The Portland

\begin{tabular}{|l|lll|}
\hline & Journal : Medium 11527 & Dispatch : 24-9-2018 & Pages : 21 \\
Article No. : $\mathbf{1 2 4 4}$ & $\square$ LE & $\square$ TYPESET \\
& MS Code : MAAS-D-17-01211 & $\cup_{\mathrm{CP}}$ & $\checkmark$ DISK \\
\hline
\end{tabular}


cement showed Blaine's specific surface and density of $495 \mathrm{~m}^{2} / \mathrm{kg}$ and $3150 \mathrm{~kg} / \mathrm{m}^{3}$, respectively.

Fly ash with a specific surface of $336 \mathrm{~m}^{2} / \mathrm{kg}$ and a density of $2320 \mathrm{~kg} / \mathrm{m}^{3}$ with the equivalent to ASTM class $F$ was used as addition to the binder material. The chemical compositions of the Portland cement and the fly ash are given in Table 1.

The Sika Viscocrete 20HE admixture used in the concrete mixtures production was a high performance superplasticizer based on polycarboxylate ether (PCE) with a specific gravity of 1.08 . The admixture was used in a constant percentage of $0.6 \%$ of the cement weight, in accordance with the manufacturer's recommendations.

\subsubsection{Aggregates}

In this study, the coarse (CNA) and fine (FNA) natural aggregates used in the production of the conventional concrete (CC) were both composed of locally-sourced crushed limestone. In the production of the recycled aggregate concretes (RC), the CNA was replaced in different percentages by one type of coarse recycled mixed aggregate (CMA) and the FNA was replaced by two different types of fine recycled aggregates, fine mixed recycled aggregate (FMA) and fine recycled ceramic aggregates (FCA).

The CMA and FMA aggregates were sourced from a local construction and demolition waste treatment plant. The composition of the CMA aggregate, determined following specification EN 933-11, showed that masonry and ceramic particles were the major component $(67 \%)$, concrete and raw aggregates being the minor components (22 and $10 \%$, respectively) and other residual components (glass, wood, plastic, gypsum, etc.) were less than $1 \%$. The FMA aggregate was obtained from the same parent C\&DW as the CMA. The FCA aggregates were produced in the laboratory via the crushing of rejected red-clay brick obtained from a brick production company in Barcelona.

Figure 1 describes the particle size distributions of all the aggregates used. A little difference existed between the particle size distribution of the CNA (the nominal sizes of $10 \mathrm{~mm}$ ) and the CMA (the nominal sizes of $12.5 \mathrm{~mm}$ ) aggregate. It can be observed that whereas the FCA and FMA had similar grading distribution, the FNA showed lower content of aggregate particles between 4 and $2 \mathrm{~mm}$. Despite those particle size distribution, the combined grading distribution employing $10 \%, 20 \%$ and $30 \%$ of the FMA and FCA in substitution of the FNA were to be in accordance with Spanish Structural concrete requirements [43].

The Physical properties of dry density and water absorption were determined according to EN specifications, as shown in Table 2. The natural aggregates had a higher density and lower absorption capacity than those of the recycled aggregates, a fact also reported by other authors [19]. The CMA, FMA and FCA had a water absorption capacity of $17.8 \%, 16 \%$ and $12.55 \%$, respectively, after submerging $24 \mathrm{~h}$ in water. However, it was determined that the CMA aggregates absorbed $70 \%$ and fine recycled aggregates (FMA and FCA) absorbed $100 \%$ of their absorption capacity at the first $30 \mathrm{~min}$, guaranteeing sufficient water storage within the aggregates as well as the desorption capacity to provide adequate internal curing, hence autogenous shrinkage reduction on the recycled aggregate concretes [15, 38, 40, 44].

The obtained crushing value of all the aggregates, are illustrated in Table 2 . The crushing value was obtained following the standard laid out in BS 812-110:1990, not exceeding 45\% for aggregate used in concrete production. An analysing of the aggregate crushing value revealed higher differences between recycled and natural aggregates. CMA showed lower toughness $(34.6 \%)$ than that of the calcite aggregates

Table 1 Chemical composition of Portland cement and fly ash and LOI

\begin{tabular}{llllllllllll}
\hline & $\begin{array}{l}\mathrm{Fe}_{2} \mathrm{O}_{3} \\
(\%)\end{array}$ & $\begin{array}{l}\mathrm{MnO} \\
(\%)\end{array}$ & $\begin{array}{l}\mathrm{TiO}_{2} \\
(\%)\end{array}$ & $\begin{array}{l}\mathrm{CaO} \\
(\%)\end{array}$ & $\begin{array}{l}\mathrm{K}_{2} \mathrm{O} \\
(\%)\end{array}$ & $\begin{array}{l}\mathrm{P}_{2} \mathrm{O}_{5} \\
(\%)\end{array}$ & $\begin{array}{l}\mathrm{SiO}_{2} \\
(\%)\end{array}$ & $\begin{array}{l}\mathrm{Al}_{2} \mathrm{O}_{3} \\
(\%)\end{array}$ & $\begin{array}{l}\mathrm{MgO} \\
(\%)\end{array}$ & $\begin{array}{l}\mathrm{Na}_{2} \mathrm{O} \\
(\%)\end{array}$ & $\begin{array}{l}\mathrm{LOI} \\
(\%)\end{array}$ \\
\hline CEM I 52.5 R & 4.67 & 0.15 & 0.18 & 64.98 & 0.57 & 0.18 & 21.91 & 3.57 & 1.45 & 0.12 & 0.91 \\
FLY ASH & 5.86 & 0.10 & 1.41 & 5.70 & 1.51 & 0.83 & 55.46 & 26.94 & 1.50 & 0.62 & 0.80 \\
\hline
\end{tabular}

\begin{tabular}{|l|lll|}
\hline & Journal : Medium 11527 & Dispatch : 24-9-2018 & Pages : 21 \\
Article No. : $\mathbf{1 2 4 4}$ & $\square$ LE & $\square$ TYPESET \\
& MS Code : MAAS-D-17-01211 & $\checkmark \mathrm{CP}$ & $\checkmark$ DISK \\
\hline
\end{tabular}


Fig. 1 Particle size distribution of aggregates

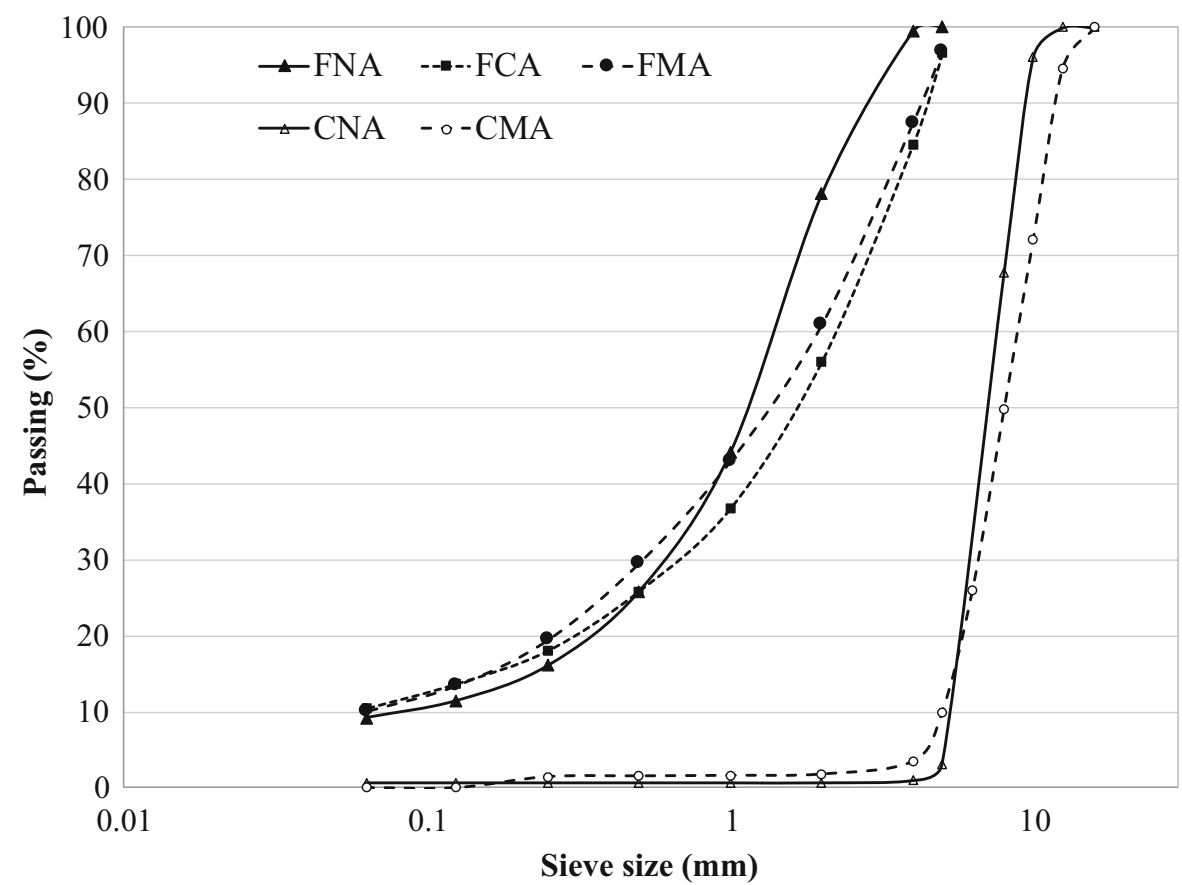

Table 2 Properties of aggregates

\begin{tabular}{llllll}
\hline & $\begin{array}{l}\text { Fine natural } \\
\text { aggregate (FNA) }\end{array}$ & $\begin{array}{l}\text { Fine mixed } \\
\text { aggregate (FMA) }\end{array}$ & $\begin{array}{l}\text { Fine ceramic } \\
\text { aggregate (FCA) }\end{array}$ & $\begin{array}{l}\text { Coarse natural } \\
\text { aggregate (CNA) }\end{array}$ & $\begin{array}{l}\text { Coarse mixed } \\
\text { aggregate (CMA) }\end{array}$ \\
\hline $\begin{array}{c}\text { Oven dried particle } \\
\text { density }\left(\mathrm{kg} / \mathrm{dm}^{3}\right)\end{array}$ & 2.59 & 1.84 & 2.09 & 2.64 & 1.79 \\
Water absorption $(\%)$ & 1.70 & 16.00 & 12.55 & 0.87 & 17.82 \\
Crushing value $(\%)$ & 18.3 & 25.1 & 22.8 & 23.1 & 34.62 \\
\hline
\end{tabular}

(23.1\%). The FCA also showed lower toughness than that of the natural fine aggregates in the crushing value test. However all the aggregates achieved the required value to be used for concrete production.

\subsection{Concrete mix design}

All concrete mixtures analysed in this study (see Table 3) were prepared and produced in the laboratory. The Bolomey dosage method $[45,46]$ was used for determining the $\mathrm{CC}$ concrete mixture. The dosage calculations began with the cement quantity and w/b ratio required. The aggregates percentage in each dosage was calculated by the Bolomey analytical method (determining the volume of each fraction, being $50 \%$ of volume coarse aggregates and other $50 \%$ of fine aggregates). The weight of each fraction employed in the concrete mix was calculated by its density. The CC concrete was produced using both FNA and CNA aggregates. Taking into consideration the results achieved in other works [15, 18], the maximum replacement up to $35 \%$ of natural aggregates by recycled aggregates was defined in order to maintain the properties of high performance concrete. The CMA aggregate was used in 15 and $30 \%$ substitutions (by volume) of the CNA aggregate for the production of the RC-15-CMA and RC-30-CMA mixtures, respectively. Both the FCA and FMA aggregates were employed in substitution of the FNA aggregate in 10\%, 20\% and 30\% (by volume) for the production of the RC-(10/20/30)-FCA and RC(10/20/30)-FMA concretes, respectively. The employment of the low percentages of recycled aggregates for concrete production was defined in order for the

\begin{tabular}{|l|lll|}
\hline & Journal : Medium 11527 & Dispatch : 24-9-2018 & Pages : 21 \\
Article No. : $\mathbf{1 2 4 4}$ & $\square$ LE & $\square$ TYPESET \\
& MS Code : MAAS-D-17-01211 & $\cup_{\mathrm{CP}}$ & $\searrow$ DISK \\
\hline
\end{tabular}


Table 3 Proportioning of the concrete mixtures. (Coded as: Conventional concrete: CC; Recycled concrete mixtures, RC$\mathrm{x}-\mathrm{y}(\mathrm{x}=$ percentage of recycled aggregate replacement level;

$\mathrm{y}=$ type of recycled aggregate used: Fine Ceramic Aggregate, FCA; Fine Mixed Aggregate, FMA; Coarse Mixed Aggregate, CMA)

\begin{tabular}{llllllcr}
\hline $\begin{array}{l}\text { Concrete } \\
\text { reference }\end{array}$ & $\begin{array}{l}\text { Cement } \\
(\mathrm{kg})\end{array}$ & $\begin{array}{l}\text { Fly ash } \\
(\mathrm{kg})\end{array}$ & $\begin{array}{l}\text { Total water } \\
(\mathrm{kg})\end{array}$ & $\begin{array}{l}\text { Fine natural } \\
\text { aggregate }(\mathrm{kg})\end{array}$ & $\begin{array}{l}\text { Coarse natural } \\
\text { aggregate }(\mathrm{kg})\end{array}$ & $\begin{array}{l}\text { Recycled } \\
\text { aggregates }(\mathrm{kg})\end{array}$ & $\begin{array}{l}\text { Effective w/b } \\
\text { ratio* }\end{array}$ \\
\hline CC & 420.0 & 40.0 & 161.0 & 912.0 & 929.7 & 0.0 & 0.32 \\
RC-10-FMA & 420.0 & 40.0 & 172.0 & 820.0 & 929.7 & 64.9 & 0.32 \\
RC-20-FMA & 420.0 & 40.0 & 182.7 & 729.6 & 929.7 & 129.7 & 0.32 \\
RC-30-FMA & 420.0 & 40.0 & 193.5 & 638.4 & 929.7 & 194.6 & 0.32 \\
RC-10-FCA & 420.0 & 40.0 & 170.2 & 820.8 & 929.7 & 73.8 & 0.32 \\
RC-20-FCA & 420.0 & 40.0 & 179.2 & 729.6 & 929.7 & 147.5 & 0.32 \\
RC-30-FCA & 420.0 & 40.0 & 188.2 & 638.4 & 929.7 & 221.3 & 0.32 \\
RC-15-CMA & 420.0 & 40.0 & 178.8 & 912.0 & 790.2 & 94.9 & 0.32 \\
RC-30-CMA & 420.0 & 40.0 & 196.3 & 912.0 & 650.8 & 189.9 & 0.32
\end{tabular}

*Effective water was calculated reducing to the Total water, the effective absorbed water amount by aggregates. This absorption capacity being 20 and $80 \%$ of their total water absorption capacity by CNA and FNA, respectively. And 70 and $100 \%$ of their total water absorption capacity of CMA and the both Fine recycled aggregates, respectively. The Natural aggregates were used dry and recycled aggregates, CMA, FMA and FCA, with a humidity of $15 \%, 16 \%$ and $11 \%$ of their absorption capacity. The "b" was the total binder determined by the sum of cement and fly ash

recycled aggregate concretes to achieve better or similar properties to those of conventional concrete, as verified by many researchers $[18,40]$. As a results of the low percentage of replacement the grading distribution of all the concrete was quite similar (see Fig. 2), no grading adjustments were carried out in any concrete production.

As shown in Table 3, the same binder amount (420 kg of cement and $40 \mathrm{~kg}$ of fly ash) was used in all the concrete mixes. The effective water-to-binder ratio, defined by Neville [33] as the ratio between the amount of free water within the mix and the amount of binder, was determined from the conventional concrete mix with the value of 0.32 , a value which was maintained constant for all recycled concrete mixes. A constant effective water-to-binder ratio is essential, in order to achieve recycled aggregate concretes with qualities comparable to those of natural aggregate concretes.

The method used by Evangelista and de Brito [47] was employed to determine the effective water (free water) amount. The water absorption capacity of aggregates submerged in water up to $30 \mathrm{~min}$ was determined and the calculation used to estimate the amount of water absorbed by the aggregates during the concrete mixing. It was considered that the coarse and fine natural aggregates absorbed 20 and $80 \%$ of their total water absorption capacity after 30 min submerged in water. The coarse mixed aggregate and fine recycled aggregates absorbed 70 and $100 \%$ of their absorption capacity. The amount of water absorbed by the aggregates were added to the mixing water as well as the free water amount. The total water amount of the concrete was considered as the amount of effective water (free water) as well as the moisture plus the absorbed water of the aggregates (see Table 3).

The humidity of the aggregates was measured, according to EN 1097-5:2000, and their absorption capacity considered at the moment of concrete production. The natural aggregates were used in dry state while the recycled aggregates were pre-wetted the day before the concrete mixing in order to reduce their absorption capacity $[2,4]$. The recycled aggregate to be used should have a high humidity value but not be in a saturated condition as that would probably result in a higher-failure risk by ITZ between the saturated recycled aggregates and the new cement paste $[2,48,49]$. The CMA, FMA and FCA aggregates were used with $15 \%, 15.8 \%$ and $11 \%$ of humidity. It was imperative to calculate the amount of water to be added to the mix, so as not to affect the effective w/c ratio and maintain the concrete's plasticity. If the recycled aggregates were not humid, they would absorb water from the paste with the following consequence of not only the loss of workability in the concrete's fresh state but also the control over the effective water/binder ratio in the paste.

The mix proportioning and the admixture amount were designed to achieve high workability concretes.

\begin{tabular}{|l|lll|}
\hline & Journal : Medium 11527 & Dispatch : 24-9-2018 & Pages : 21 \\
Article No. : $\mathbf{1 2 4 4}$ & $\square$ LE & $\square$ TYPESET \\
& MS Code : MAAS-D-17-01211 & $\square_{\mathrm{CP}}$ & $\checkmark$ DISK \\
\hline
\end{tabular}




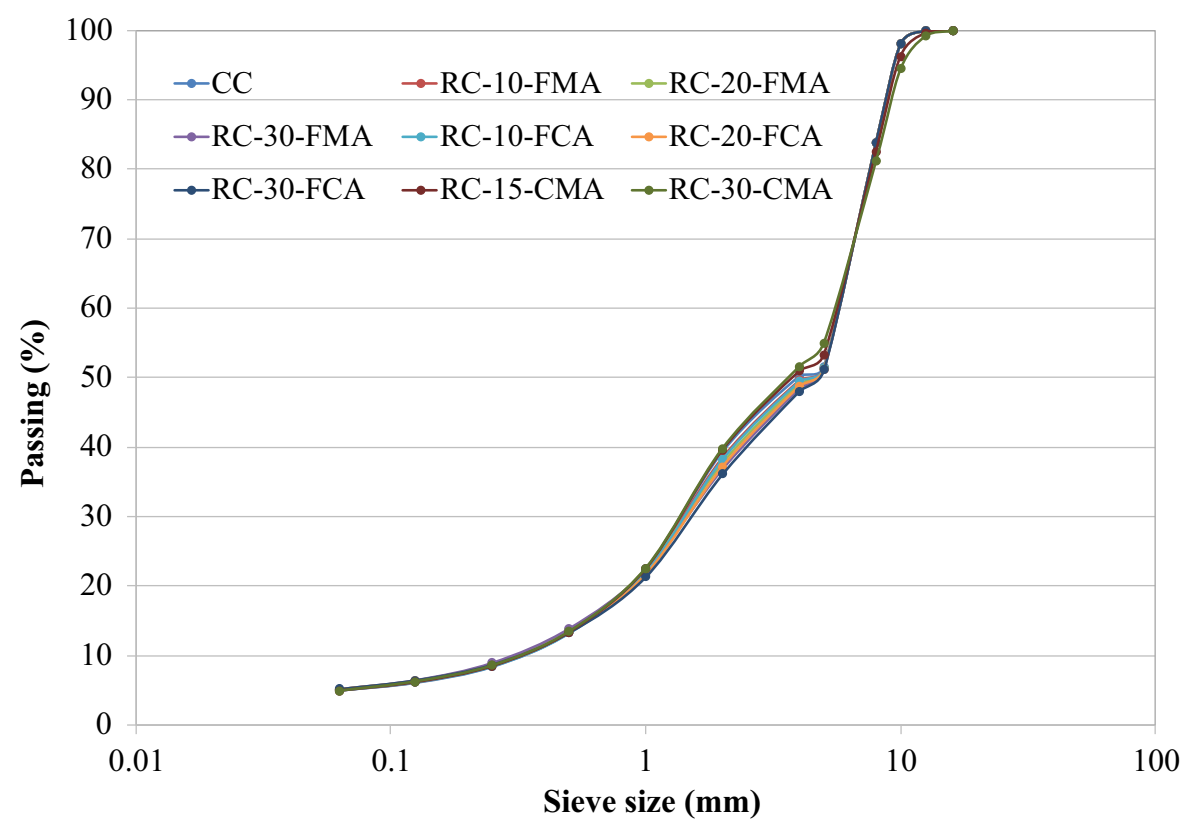

Fig. 2 Grading distribution of all the concretes

413 The amount of chemical admixture added was kept 414 constant at $0.6 \%$ of the cement weight for all concrete 415 mixtures. The slump cone test results were registered 416 in the range of $100-120 \mathrm{~mm}$ (S3 class following the 417 EN 206-1:2000 standard).

\subsection{Testing programme}

\subsubsection{Density, absorption and volume of permeable pore space}

The density, absorption and voids were measured following the ASTM C 642-97 "Standard Test Method for Density, Absorption, and Voids in Hardened Concrete" at 28 days. Three $100 \mathrm{~mm}$ cubic specimens were used in this test for each type of concrete produced to obtain the average values.

\subsubsection{Compressive, splitting tensile strengths and elastic modulus}

The mechanical properties of concretes were determined using a compression machine with a loading capacity of $3000 \mathrm{kN}$. The mechanical properties were measured by using $200 \times \varnothing 100 \mathrm{~mm}$ cylinder specimens. The compressive strength was measured at the ages of 7, 28 and 180 days following the EN 12390-3 standard. The splitting tensile strength and modulus of elasticity were tested at 28 days, also following EN 12390-6 and EN 12390-13 specifications, respectively. Three specimens were used for each type of concrete produced.

\subsubsection{Shrinkage}

2.3.3.1 Plastic shrinkage The plastic shrinkage strain was determined using the method proposed by Saliba et al. [50]. The plastic shrinkage strain was measured with LVDTs which were connected to a data acquisition system. The LVDTs' length of charge was recorded every minute for $24 \mathrm{~h}$ after concrete casting. The steel mould used in this experiment was a square prism of $600 \times 150 \times 150 \mathrm{~mm}$ covered with Teflon sheeting. One side of the concrete specimen was embedded in the mould while the other side was left exposed to a free-moving Teflon plate via the use of 4 steel rebars $(\varnothing 10 \mathrm{~mm})$ in each side (see Fig. 3). The LVDT was setup on the mould's remaining steel plate and it was in direct contact with the free-moving Teflon plate. The plastic strain measurements started immediately after concrete casting, in order to record all the linear length changes up to the concrete's setting time. The test specimens were kept under the same conditions of $25 \pm 2{ }^{\circ} \mathrm{C}$ and temperature and

\begin{tabular}{|l|lll|}
\hline & Journal : Medium 11527 & Dispatch : 24-9-2018 & Pages : 21 \\
Article No. : $\mathbf{1 2 4 4}$ & $\square$ LE & $\square$ TYPESET \\
& MS Code : MAAS-D-17-01211 & $\checkmark \mathrm{CP}$ & $\checkmark$ DISK \\
\hline
\end{tabular}


$50 \pm 5 \%$ relative humidity for the entire test period.

461 Two specimens from each concrete mixture were 462 tested and their mean value was reported.

\subsubsection{Autogenous shrinkage An Autogenous} shrinkage test was conducted in all concrete mixtures for 28 days after concrete casting. Following the recommendations of the Japan Concrete Institute (JCI) [51] strain gauges were vertically embed in the concrete specimens using cylindrical moulds of $300 \times \varnothing 150 \mathrm{~mm}$. After casting, the free upper surfaces of the moulds were immediately covered with two layers of adhesive aluminium foil in order to prevent moisture loss from the concrete specimen. The specimens in sealed state were connected to the data acquisitions system approximately $10 \mathrm{~min}$ after casting. The samples were stored in the climatic chamber at $25 \pm 2{ }^{\circ} \mathrm{C}$ and $50 \pm 5 \%$ of humidity. After $24 \mathrm{~h}$, the specimens were removed from their moulds, sealed with adhesive aluminium foil and connected again to the data acquisition system for up to 28 days. Each value presented represents the average of two specimens tested for each concrete mixture.

\subsubsection{Drying shrinkage The drying shrinkage was} determined following the ASTM C596 standard using $70 \times 70 \times 285 \mathrm{~mm}$ prismatic specimens. The specimens, after being covered with a wet burlap and plastic sheet during the initial $24 \mathrm{~h}$, were demoulded and submerged for 3 days in water. The first length measurement was taken and they were placed in the climatic chamber at $25 \pm 2{ }^{\circ} \mathrm{C}$ and $50 \pm 5 \%$ of humidity. The length change of the prismatic specimens was measured at $4,7,14$ and
28 days in accordance with ASTM C596 and then extended up to 150 days. The weight loss of the prismatic specimens was also registered at the same time periods. Each result was the average obtained from testing three specimens per concrete mixture.

\subsubsection{Chloride ion penetrability}

The chloride penetrability of the concrete was determined in accordance with ASTM C1202 using a $50 \times \varnothing 100 \mathrm{~mm}$ water-saturated concrete section obtained by the extraction of a disk from the centre of a $200 \times \varnothing 100 \mathrm{~mm}$ concrete cylinder. In this study, the chloride ion penetrability test was carried out on the concrete specimens at the ages of 28 days and each result was the average of the four measurements taken.

\section{Results and discussion}

3.1 Density, absorption and volume of permeable pore space

The results of dry-density, water absorption and volume of permeable space are shown in Table 4. In considering the concretes made with fine and coarse RMA aggregates (RC-10/20/30-FMA and RC-15/30CMA, respectively), it was determined that drydensity decreased and water absorption and porosity increased as the replacement ratios increased. Both the absorption capacity and the volume of the accessible pores remained similar or lower to those obtained from the conventional concrete with the use of 10 or 20 of FMA and $15 \%$ of CMA, respectively. The use of higher replacement ratio of $30 \%$ led to lower physical
498

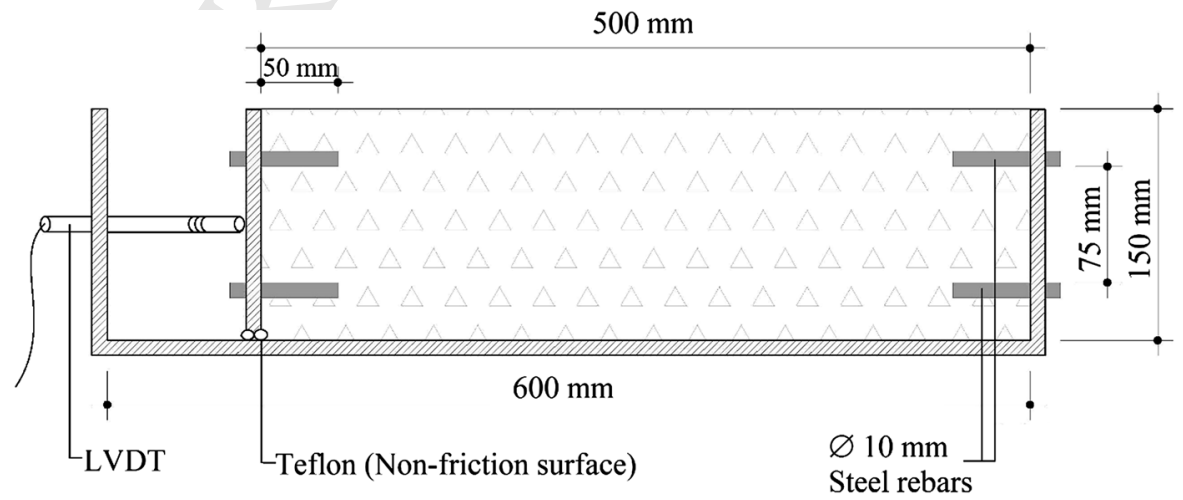

Fig. 3 Plastic shrinkage test specimen and setup [25]

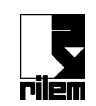

\begin{tabular}{|l|lll|}
\hline & Journal : Medium 11527 & Dispatch : 24-9-2018 & Pages : 21 \\
Article No. : $\mathbf{1 2 4 4}$ & $\square$ LE & $\square$ TYPESET \\
& MS Code : MAAS-D-17-01211 & $\square_{\mathrm{CP}}$ & $\checkmark$ DISK \\
\hline
\end{tabular}


properties of up to $20 \%$. The higher content in mortar attached to the old raw aggregates as well as a higher content in masonry particles in the recycled aggregates should result in a decrease of the physical properties of the recycled aggregate concrete [19, 52].

In contrast, the recycled aggregate concretes produced containing FCA were found to have a slightly higher density than those of the concretes produced employing FMA, but lower than that of CC concrete. The absorption and permeable pore volume of concretes made with FCA were between 3 and 10\% lower than those of $\mathrm{CC}$, a fact also reported in previous studies [16]. The FCA showed a slightly higher amount of $<1 \mathrm{~mm}$ particles than that of the fine natural aggregate, a determining factor which led on to a better compactness and improvement of the durability properties [53]. Additionally, denser ITZ (see Fig. 4) could have been developed due to an improved hydration by fine ceramic aggregates, a fact also described in a previous work [18]. These fine ceramic aggregates probably acting as internal curing agents, enhanced of cement hydration increasing $\mathrm{C}-\mathrm{S}-\mathrm{H}$ content and lower water absorption capacity of hardened concrete [54].

\subsection{Compressive, splitting tensile strengths and modulus of elasticity}

The mechanical properties of compressive strength at 7, 28 and 180 days, and splitting tensile strength and modulus of elasticity at 28 days are shown in Table 5.

Most of the recycled concrete mixtures containing recycled mixed aggregates (FMA and CMA) obtained similar compressive strength results to those obtained from CC concrete at 7 days of age. Only the $30 \%$ replacement of CMA considerably decreased the compressive strength, due to the lower toughness of the CMA and the influence of their higher nominal size [55] when compared to that of the natural aggregates.

However when the FCA aggregates were used to replace the fine natural aggregates, the 7-day compressive strength improved by up to $7.5 \%$, even when the replacement ratios reached $30 \%$. Probably caused by the influence of a higher compactness of the mortar paste due to the grading distribution of FCA [56].

Figure 5 shows the relative compressive strength of the recycled concretes with respect to that of the CC concrete at 28 days. It was determined that whereas the concretes made employing the FMA aggregates showed a similar compressive strength to that of $\mathrm{CC}$ concrete, the concrete employing the CMA aggregate showed slightly lower compressive strength at 28 days of curing. The poorer quality of the mortar attached to the raw aggregates in recycled coarse aggregates had a noticeable negative influence when the replacement was increased by $15 \%$ of coarse aggregates. This effect was not detected by Bui et al. [40] when the coarse recycled aggregates were made up of $100 \%$ ceramic tiles. However, at 28 days of curing the recycled aggregate concretes produced with the FCA aggregates not only showed the highest values of compressive strength but also the highest compressive strength evolution from 7 to 28 days of curing. An improved ITZ between the FCA aggregate and cement paste and the absence of old ITZ (see Fig. 4) contributed to the improvement of the compressive strength. In addition, the water contained in the FCA aggregates could, in advanced stages of hydration,

Table 4 Physical properties of hardened concretes at 28 days

\begin{tabular}{llll}
\hline Concrete reference & Dry density $\left(\mathrm{kg} / \mathrm{dm}^{3}\right)$ & Water absorption $(\%)$ & Volume accessible pores $(\%)$ \\
\hline CC & 2.39 & 2.62 & 6.25 \\
RC-10-FMA & 2.38 & 2.47 & 5.88 \\
RC-20-FMA & 2.37 & 2.72 & 6.45 \\
RC-30-FMA & 2.33 & 3.03 & 7.07 \\
RC-10-FCA & 2.38 & 2.37 & 5.62 \\
RC-20-FCA & 2.36 & 2.44 & 5.77 \\
RC-30-FCA & 2.35 & 2.54 & 5.97 \\
RC-15-CMA & 2.39 & 2.54 & 6.05 \\
RC-30-CMA & 2.33 & 3.2 & 7.48 \\
\hline
\end{tabular}

\begin{tabular}{|l|lll|}
\hline Aournal : Medium 11527 & Dispatch : 24-9-2018 & Pages : 21 \\
& Article No. : $\mathbf{1 2 4 4}$ & $\square$ LE & $\square$ TYPESET \\
& MS Code : MAAS-D-17-01211 & $\checkmark$ CP & $\checkmark$ DISK \\
\hline
\end{tabular}



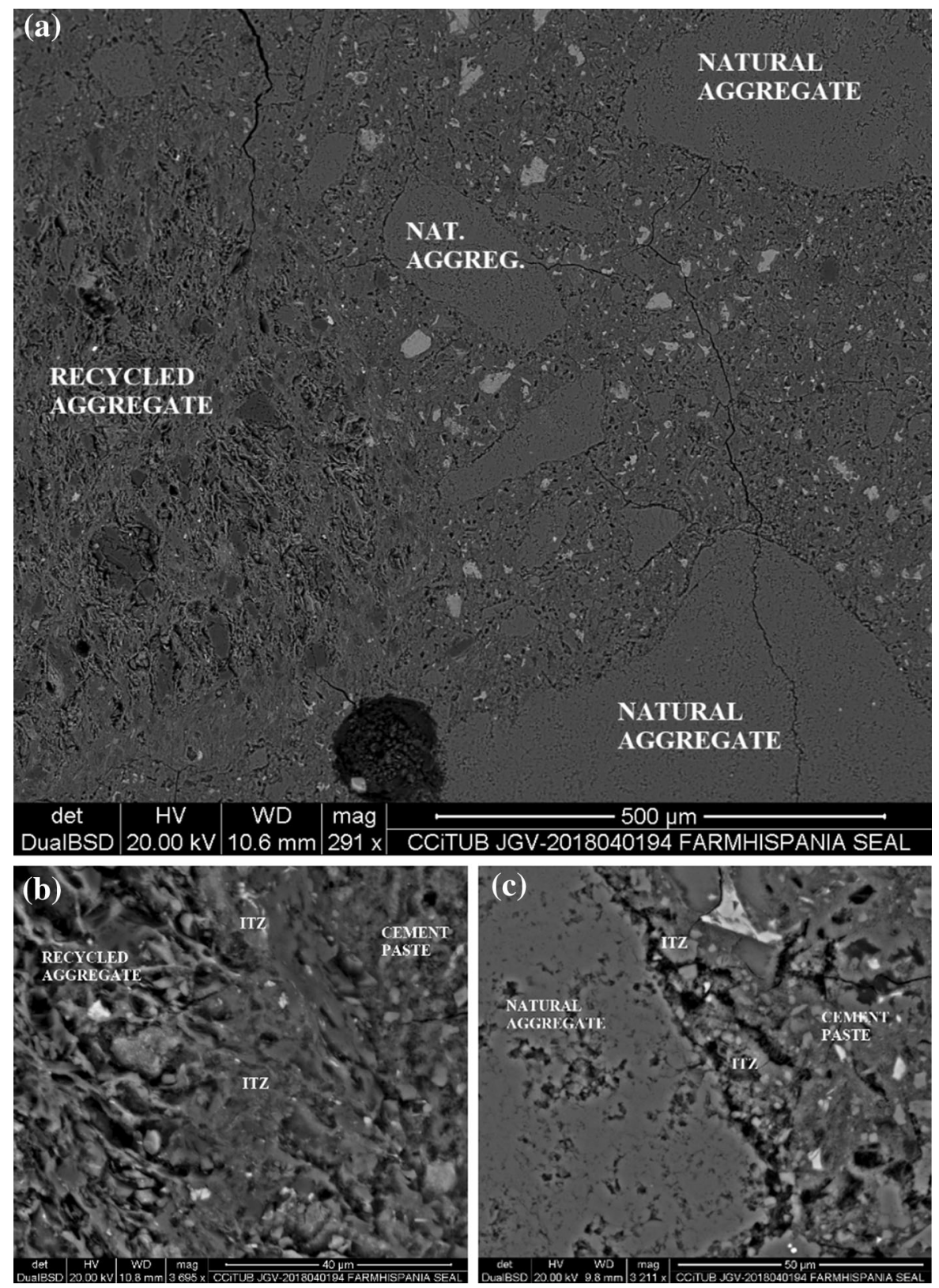

Fig. 4 a General imaging of a recycled aggregate concrete, different types of ITZ are shown; b Ceramic aggregate ITZ in recycled concrete; $\mathbf{c}$ Usual natural aggregate ITZ of the $\mathrm{CC}$ concrete

supply the water for hydration to the cement paste, thus improving the concrete's properties [49, 57]. Internal curing is also beneficial for the mechanical properties as it not only acts as a water source on water-scarce cement hydration reactions but also spreads cement matrix densification, thus increasing long-term compressive strength [15, 31, 32].
Over longer periods, the negative effect of recycled mixed aggregate with respect to their compressive strength properties proved to be more significant, especially when CMA aggregates were employed for concrete production. Results obtained showed that the compressive strength values decreased by up to $14 \%$ in comparison to those of the CC concrete (see Fig. 5). In contrast, the recycled aggregate concretes

\begin{tabular}{|l|lll|}
\hline & Journal : Medium 11527 & Dispatch : 24-9-2018 & Pages : 21 \\
Article No. : $\mathbf{1 2 4 4}$ & $\square$ LE & $\square$ TYPESET \\
& MS Code : MAAS-D-17-01211 & $V_{\mathrm{CP}}$ & $\checkmark$ DISK \\
\hline
\end{tabular}


Table 5 Results from the mechanical property tests of compressive strength (at 728 and 180 days), splitting tensile strength and modulus of elasticity (at 28 days) with their Standard Deviation

\begin{tabular}{|c|c|c|c|c|c|c|c|}
\hline \multirow[t]{2}{*}{ Concrete reference } & \multicolumn{3}{|c|}{$\begin{array}{l}\text { Compressive strength }(\mathrm{MPa}) \\
\text { (Standard Deviation }(\mathrm{MPa}))\end{array}$} & \multicolumn{2}{|c|}{$\begin{array}{l}\Delta \text { Compressive } \\
\text { Strenght }(\%)\end{array}$} & \multirow{2}{*}{$\begin{array}{l}\text { Splitting Tensile } \\
\text { Strength }(\mathrm{MPa}) \\
(\text { Standard } \\
\text { deviation }(\mathrm{MPa})) \\
28 \text { days }\end{array}$} & \multirow{2}{*}{$\begin{array}{l}\text { Modulus of } \\
\text { Elasticity } \\
(\mathrm{GPa}) \text { (Standard } \\
\text { Deviation } \\
(\mathrm{MPa})) \\
28 \text { days }\end{array}$} \\
\hline & 7 days & 28 days & 180 days & 7-28 days & 28-180 days & & \\
\hline $\mathrm{CC}$ & $78.15(5.10)$ & $82.63(6.42)$ & $96.75(10.31)$ & 5.73 & 17.09 & $3.95(0.49)$ & $42.43(4.02)$ \\
\hline RC-10-FMA & $75.84(2.39)$ & $81.07(5.83)$ & $87.48(7.25)$ & 6.90 & 7.91 & $4.00(0.63)$ & $43.26(0.50)$ \\
\hline RC-20-FMA & $77.37(1.72)$ & $83.84(7.72)$ & $97.82(8.14)$ & 8.36 & 16.67 & $3.87(0.32)$ & $38.94(0.11)$ \\
\hline RC-30-FMA & $77.00(2.84)$ & $89.12(1.38)$ & $93.08(2.06)$ & 15.74 & 4.44 & $4.08(0.31)$ & $37.80(0.10)$ \\
\hline RC-10-FCA & $76.27(3.85)$ & $86.52(4.61)$ & $106.00(1.03)$ & 13.44 & 22.52 & $3.98(0.38)$ & $41.62(1.10)$ \\
\hline RC-20-FCA & $84.04(0.51)$ & $88.52(4.52)$ & $113.05(5.45)$ & 5.33 & 27.71 & $4.17(0.77)$ & $41.21(2.17)$ \\
\hline RC-30-FCA & $82.90(2.94)$ & $93.84(3.47)$ & $112.13(3.56)$ & 13.20 & 19.49 & $3.76(0.66)$ & $41.44(0.66)$ \\
\hline RC-15-CMA & $75.22(5.87)$ & $79.32(4.13)$ & $91.89(10.10)$ & 5.45 & 15.85 & $3.62(0.52)$ & $41.23(0.35)$ \\
\hline RC-30-CMA & $72.97(4.52)$ & $80.76(6.70)$ & $83.62(7.14)$ & 10.68 & 3.54 & $2.57(0.12)$ & $40.36(0.97)$ \\
\hline
\end{tabular}

Fig. 5 Relative compressive strength of recycled aggregate concretes at 28 and 180 days in comparison with conventional concrete compressive strength at 28 days

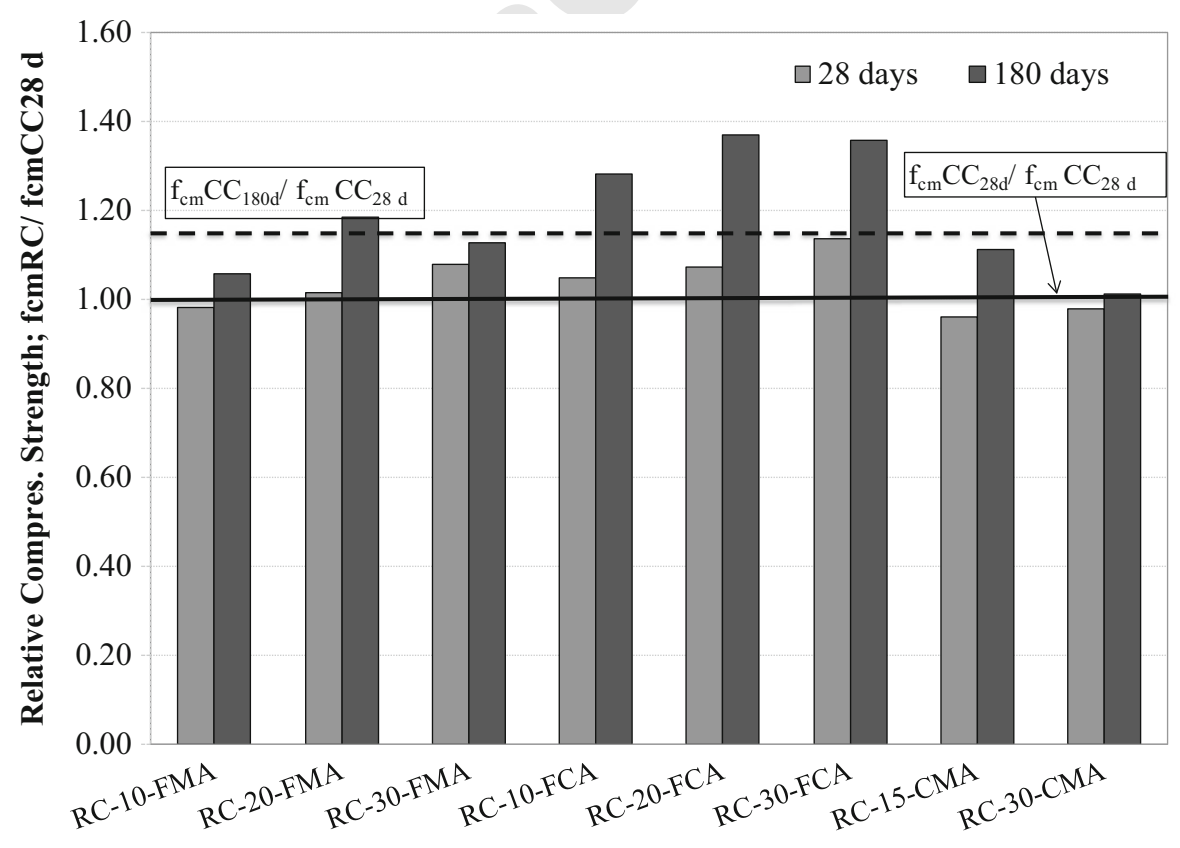

high strength concrete [58]. The recycled concretes with fine aggregates showed splitting tensile strengths that represented $5 \%$ of their compressive strength, a fact also reported by the ACI [59] for HPC containing natural aggregates. However, those concretes containing CMA aggregates achieved a 10-35\% lower splitting tensile strength $[14,16]$. The results achieved by concrete produced employing the FMA and CMA aggregates, which were sourced from the same parent
613

614

615

616

617

618

619

620

621

611 values to that of the CC concrete and those values

\begin{tabular}{|l|lll|}
\hline & Journal : Medium 11527 & Dispatch : 24-9-2018 & Pages : 21 \\
Article No. : $\mathbf{1 2 4 4}$ & $\square$ LE & $\square$ TYPESET \\
MS Code : MAAS-D-17-01211 & $\bigcup_{\mathrm{CP}}$ & $\searrow$ DISK \\
\hline
\end{tabular}


C\&DW, showed that the splitting tensile strength was far more influenced by the use of coarser aggregates.

It is known that the lower density of recycled aggregates causes a lower modulus elasticity of recycled aggregates concrete in comparison to that of conventional concretes [40,60,61]. Despite the fact that all the recycled aggregates concretes showed a slightly lower elastic modulus value to that found in the $\mathrm{CC}$ concrete, it was determined that all the recycled aggregates concretes achieved high elastic modulus values of between 35 and $45 \mathrm{GPa}$ which are within the standard range for high strength concretes [59]. The concretes produced employing the FCA aggregates not only achieved similar properties to those of the $\mathrm{CC}$ but also showed a lower influence on this property with respect to the increased replacement when compared with the values obtained from concretes produced with recycled mixed aggregates (RMA).

\subsection{Shrinkage}

\subsubsection{Plastic shrinkage}

The results from monitoring the shrinkage strain for the initial $24 \mathrm{~h}$ are shown in Fig. 6. All concretes showed a similar behaviour, which was characterized through four different stages. The first stage is an initial short expansion, which could be extends up to the first hour. After the initial expansion, the highest slope of shrinkage strain was recorded up to approximately $4 \mathrm{~h}$ after casting. The cracking could spread if the surface tension and capillary pore stress increase as a cause of the evaporation of superficial water and the tensile strength of the concrete is not sufficiently developed [62]. A second expansion stage was observed for the following 4-6 $\mathrm{h}$ and a last shrinkage period, which showed a lower strain rate, was extended until the test completion at $24 \mathrm{~h}$.

In the first stage, the swelling effect, which generates the small expansion registered during the dormant period [50] could be due to the settlement of the concrete's components, water reallocation and the water released from aggregates. The high desorption of water from aggregates [63] caused the highest, but low value, expansions (35-45 microstrains) in RA-30FMA concrete.

The second stage is the most critical stage with regard to potential cracking which corresponds to the highest shrinkage strain rate. In this stage, granular interactions are gradually favored by consolidation, increase of solids volume (hydration) and decrease of water content (consolidation, hydration, evaporation). Thus volumetric contractions are little by little transmitted horizontally. The produced recycled concretes showed a significant reduction of plastic shrinkage in comparison to $\mathrm{CC}$ concrete, especially when the concretes were produced employing RMA aggregates. The concretes produced with the CMA and FMA aggregates achieved a shrinkage value between 50-110 and 70-125 microstrains, respectively. This decrease in the shrinkage development could be explained by varying factors. The aggregates with a high capacity of water accumulation, their water desorption capacity and a delay in initial setting time [64] decreased the internal friction angle. The concretes produced with the FCA aggregates showed slightly higher peaks (110-200 microstrains) than those produced with recycled mixed aggregate. But the FCA concretes also achieved lower shrinkage values than those of the $\mathrm{CC}$ concrete $(225$ microstrains). However, none of the concretes examined in this study exceeded the threshold value (1100 microstrains) proposed by Baghabra et al. [65] as high-risk of cracking strain.

All concrete mixtures went through a second expansion stage after 4-5 h of concrete casting which continued for an additional 4-6 h, which corresponded with the setting time. The expansion recorded during this period represented $5-20 \%$ of the strain registered in the previous stage and in all probability was a result of the cement hydration process as an initiation of the setting time as well as an increase of interior temperature [50], which caused the release of water from the aggregates, thus leading to a slight expansion. During the final stage, all the recycled aggregate concretes achieved, after $11-13 \mathrm{~h}$ of casting, the maximum shrinkage strain obtained at the second stage, while the conventional concrete obtained that value after $10 \mathrm{~h}$. At the test's completion, the conventional concrete showed 25-100\% higher shrinkage strain than that achieved by the recycled aggregate concretes. As certain studies have reported $[60,66,67]$ the use of lightweight and RMA aggregates can significantly reduce the plastic shrinkage cracking risk.

\begin{tabular}{|l|lll|}
\hline & Journal : Medium 11527 & Dispatch : 24-9-2018 & Pages : 21 \\
Article No. : $\mathbf{1 2 4 4}$ & $\square$ LE & $\square$ TYPESET \\
& MS Code : MAAS-D-17-01211 & $\square_{\mathrm{CP}}$ & $\checkmark$ DISK \\
\hline
\end{tabular}


Fig. 6 Plastic shrinkage results up to $24 \mathrm{~h}$; fine recycled aggregate concrete (top) and coarse recycled aggregate concretes (bottom)
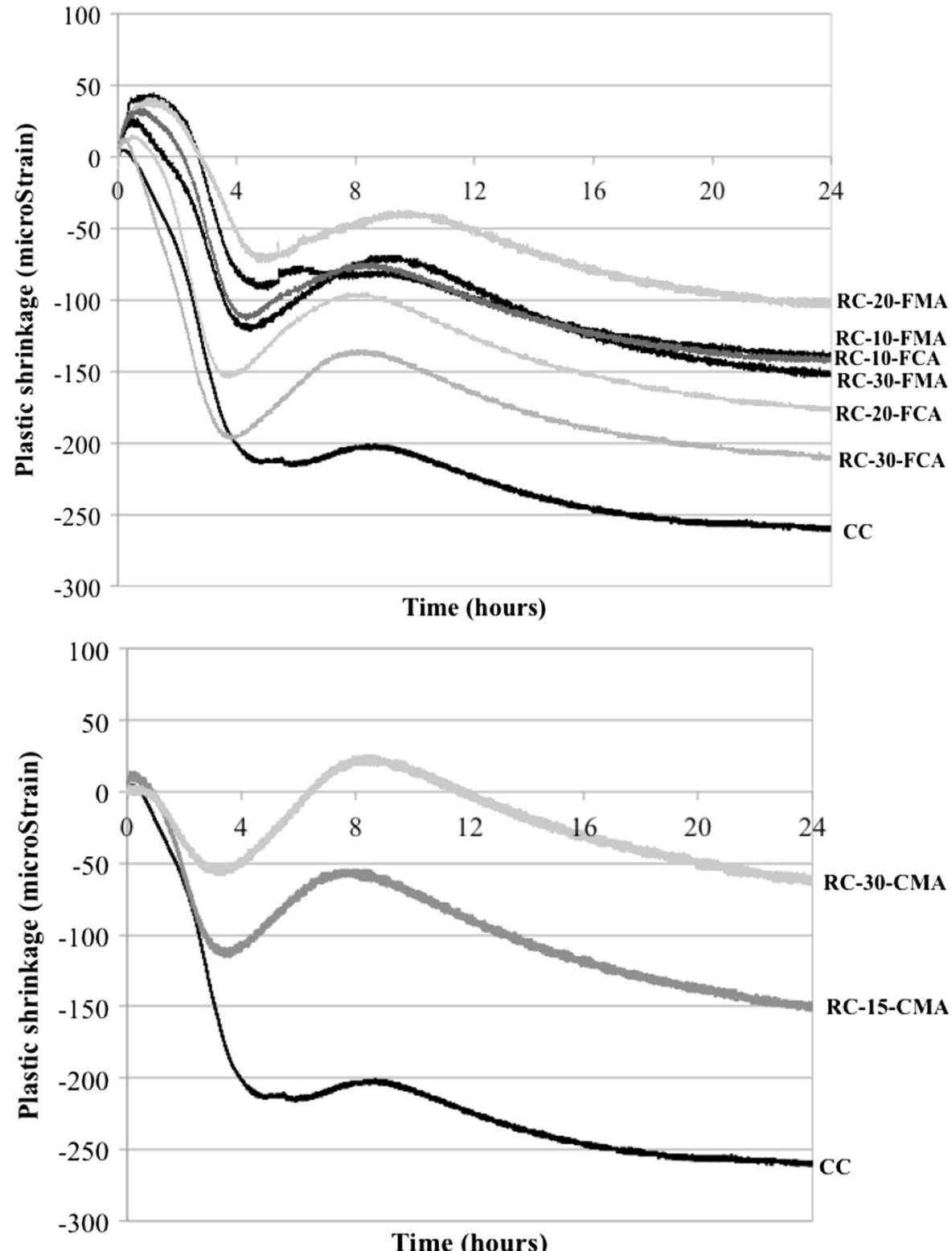

\subsubsection{Autogenous shrinkage}

The time zero (the moment when effective shrinkage strains start to develop internal tensile stress in hardening cement paste) is usually considered as starting from the initial setting time, the end of the dormant period, the threshold of solidification and the maximum rate of deformation [68]. In the case in question, the strain measurements started (time zero) was considered immediately after the casting and sealing of the concrete moulds following the method employed by Suzuki et al. [15], JCI committee [51] and Meddah and Sato [68] in order to ensure comparable testing conditions between all concretes. The results registered during the first $24 \mathrm{~h}$ and up to 28 days are presented in Fig. 7.

All concretes had an initial dormant stage in which the concretes showed non-shrinkage behaviours or even slight expansions. This dormant period was extended up to the initial 4-6 h as a result of a barrier effect on the cement hydration which was enhanced by the mixture composition, which contained an addition

\begin{tabular}{|l|lll|}
\hline & Journal : Medium 11527 & Dispatch : 24-9-2018 & Pages : 21 \\
Article No. : $\mathbf{1 2 4 4}$ & $\square$ LE & $\square$ TYPESET \\
& MS Code : MAAS-D-17-01211 & $\cup_{\mathrm{CP}}$ & $\searrow$ DISK \\
\hline
\end{tabular}


of fly-ash [69]. While in a previous study [44] high performance concrete made with rapid hardening cement and recycled concrete aggregates did not show dormant periods when the autogenous shrinkage was assessed, in this case a higher amount of total water coupled with fly-ash addition could be responsible for reducing the autogenous shrinkage during the initial hours of curing. In addition, the use of highly porous aggregates, such as FMA, FCA and CMA aggregates for concrete production, which contained a higher amount of absorbed water than that of the natural aggregates, resulted in considerable initial swellings of up to 75 microstrains. These values proved to be similar to the values obtained in other studies in which ceramic aggregates were employed as internal curing agents [15].

In a period between 4 and $10 \mathrm{~h}$ after casting, the $\mathrm{CC}$ concrete and concretes employing FCA aggregates showed the highest shrinkage rates as a result of the water consumption caused by cement hydration reactions from the capillary pores $[33,69]$. The autogenous shrinkage results of the $\mathrm{CC}$ concrete showed quicker development and a higher autogenous shrinkage rates than those of the FCA concretes. Capillary-water menisci increases capillary pore stresses with the consequent effect of producing a reduction of the capillary pore volume [70]. In contrast, the recycled aggregate concrete produced employing FMA and CMA aggregates continued to swell during this period and did not suffer any volume reduction prior to the concretes' setting.

After $10 \mathrm{~h}$ of casting, the CC concrete reached $60 \%$ of its ultimate autogenous shrinkage value of -150 microstrains, (see Fig. 7). Recycled concrete containing FCA aggregates showed very similar results to those found by Suzuki et al. [15]. The increase in the amount of the FCA aggregate within the concrete significantly reduced the development of its autogenous shrinkage. In fact when the replacement level was $30 \%$ almost no shrinkage level was reached. The effect of the water released was even more prominent when more porous mixed recycled aggregates were used. The concrete produced employing FMA aggregates showed very slight shrinkage slopes from 1 to 28 days. These shrinkage slopes did not counteract the initial expansion levels and revealed ultimate expansive strains at 28 days. The expansion effect increased with the employment of CMA aggregate, which throughout the entire test duration showed a none- shrinking behaviour for replacement levels of up to $30 \%$. As Zhutovsky et al. [27, 31] described, the ultimate shrinkage value depends on the amount of water stored in the aggregates' pore network and their pore size distribution and connectivity. The saturated aggregates act as internal curing agents, thus reducing or even cancelling the autogenous shrinkage. The capillary stresses created within the pores due to cement hydration are diminished by the transfer and incorporation of water from the almost saturated recycled aggregates to the new cement paste via capillarity. The higher porosity of the recycled mixed aggregates (RMA) eased the capillary water transportation to the new cement paste. The optimum content of the recycled aggregates with respect to obtaining shrinkage reduction is strongly related to the $w / b$ of the mixture and desorption capacity of the recycled aggregates $[15,38,71]$. Thus, the employment of high percentages of RMA aggregates caused an expansion, within the concrete due to the high excess of water within those aggregates. In addition, due to the high heterogeneity of those mixed aggregates, their behavior was far more difficult to control than that of the ceramic aggregates. In addition, the RC-30-FMA concrete specimens for the autogenous test were produced several hours later than the concretes RC-10/20-FMA, in all probability the humidity of the RMA employed for production of RC-30-FMA was lower than $15.8 \%$, and consequently that concrete did not suffer the expansion, thus guaranteeing the possibility of employment the RMA aggregates also to control de autogenous shrinkage.

\subsubsection{Drying shrinkage}

The drying shrinkage results from all 9 concrete mixes from 1 day to 150 days after casting are plotted in Fig. 8. As can be observed, the shrinkage increase occurred mainly in the early ages, tending to stabilize afterwards. The CC concrete presented the lowest drying shrinkage for the entire test duration.

Drying shrinkage depends on the water-to-binder ratio, the paste content, the restraining effect of aggregates on cement paste shrinkage and modulus of elasticity. The drying shrinkage results from the RCs can be explained by the higher presence of cement paste and also the higher amount of pores and their interconnection [36, 37, 44, 72-75]. Higher

\begin{tabular}{|l|lll|}
\hline & Journal : Medium 11527 & Dispatch : 24-9-2018 & Pages : 21 \\
Article No. : $\mathbf{1 2 4 4}$ & $\square$ LE & $\square$ TYPESET \\
& MS Code : MAAS-D-17-01211 & $\square_{\mathrm{CP}}$ & $\checkmark$ DISK \\
\hline
\end{tabular}



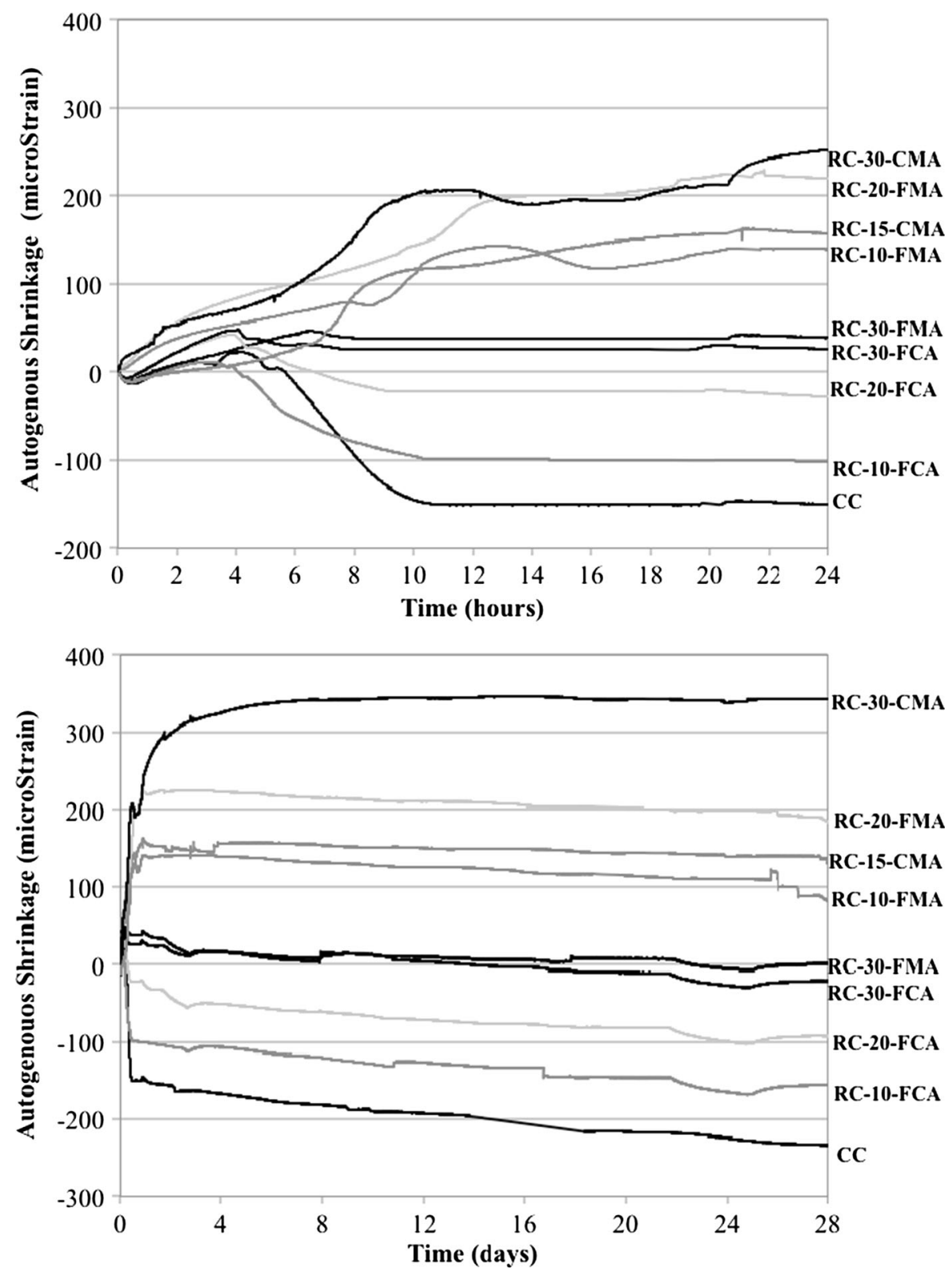

Fig. 7 Autogenous shrinkage results up to $24 \mathrm{~h}$ (top) and up to 28 days (bottom) of conventional concrete and fine and coarse recycled aggregate concretes

porosity is a fundamental factor with respect to the higher shrinkage rates of RC concrete when compared with CC concretes. Furthermore, the modulus of elasticity from the RCs was lower than that of the $\mathrm{CC}$ concrete (see Table 5), resulting in less stiffness concretes. However, a comparison of these values with respect to those summarized by Silva et al. [42], concluded that the influence of the modulus of elasticity in the drying shrinkage is more important in low/medium-strength concretes than in high performance concretes.

Table 6 shows the shrinkage values, mass loss (\%) and the ratio of the shrinkage value of recycled aggregates concretes with respect to that of the $\mathrm{CC}$ concrete at 7,28 and 150 days as well as the increase of shrinkage of each type of concrete from 7 to 28 days and for 7 days to 150 days. The shrinkage values of $\mathrm{RC}$ concretes at 7 days were between 50 and $120 \%$

\begin{tabular}{|l|lll|}
\hline & Journal : Medium 11527 & Dispatch : 24-9-2018 & Pages : 21 \\
Article No. : $\mathbf{1 2 4 4}$ & $\square$ LE & $\square$ TYPESET \\
MS Code : MAAS-D-17-01211 & $\checkmark$ CP & $\checkmark$ DISK \\
\hline
\end{tabular}


higher than that of $\mathrm{CC}$ concrete, in all probability due to loss of water from the concrete as well as the release of water from the recycled aggregates to the cement paste, thus reducing the stiffness of the concretes [76]. However, at 28 and 150 days of testing, the drying shrinkage values of the RAC concretes were in general only $20-35 \%$ and $15-30 \%$ higher than that of the CC concrete, respectively. In addition, the CC concrete suffered an increase of drying shrinkage of 134 and $227 \%$ from 7 to 28 days and from 7 to 150 days, respectively, with respect to the value obtained at 7 days. Those values were higher than those achieved by the concretes produced with recycled aggregates over the same time, revealing an adequate behaviour of those concretes.

Over the longer term, the internal curing effect of the recycled aggregates, acting as water reservoirs, counteract the water-loss on evaporation by providing a water to cement matrix from the aggregate pore network similarly to that obtained by lightweight aggregates [31]. This tendency contrasts with the findings presented by Pedro et al. [36] which show that the RAC mixes had higher increases of shrinkage at older ages. However, in the tests carried out by Pedro et al. the recycled aggregates were much less porous.

\subsubsection{Chloride-ion penetration}

Chloride-ion penetration test results at 28 and 180 days of curing are shown in Fig. 9. All the results obtained from the conventional and recycled aggregate concretes were found to be within the cumulative charge range corresponding to low corrosion risk at 28 days and certain concretes achieved the very low risk value at 180 days according to the ASTM C1202 specification. However, in general the resistance to chloride-ion penetration decreased when the recycled aggregate content increased and their quality decreased, a fact also reported in several other studies $[14,16,41,72,74,77]$.

At 28 days, the CC concrete had a total charge passing of $1108 \mathrm{C}$, whereas the recycled concrete employing the FMA and CMA aggregates showed an increase of 453-581 and 467-599 C respectively on that total charge of the $\mathrm{CC}$ concrete. In contrast, the concrete produced employing the FCA aggregates obtained results which proved to be closer to those of the CC. The concrete produced employing 30\% of FCA aggregates achieved a passing charge of $1235 \mathrm{C}$, having a higher resistance value than that of concrete made with 10 and $20 \%$ of FCA aggregates. The higher porosity and water absorption capacity of the recycled
876

877

878

879

880

881

882

883

884

885

886

887

888

889

890

891

892

893

894

895

896

897

898

899

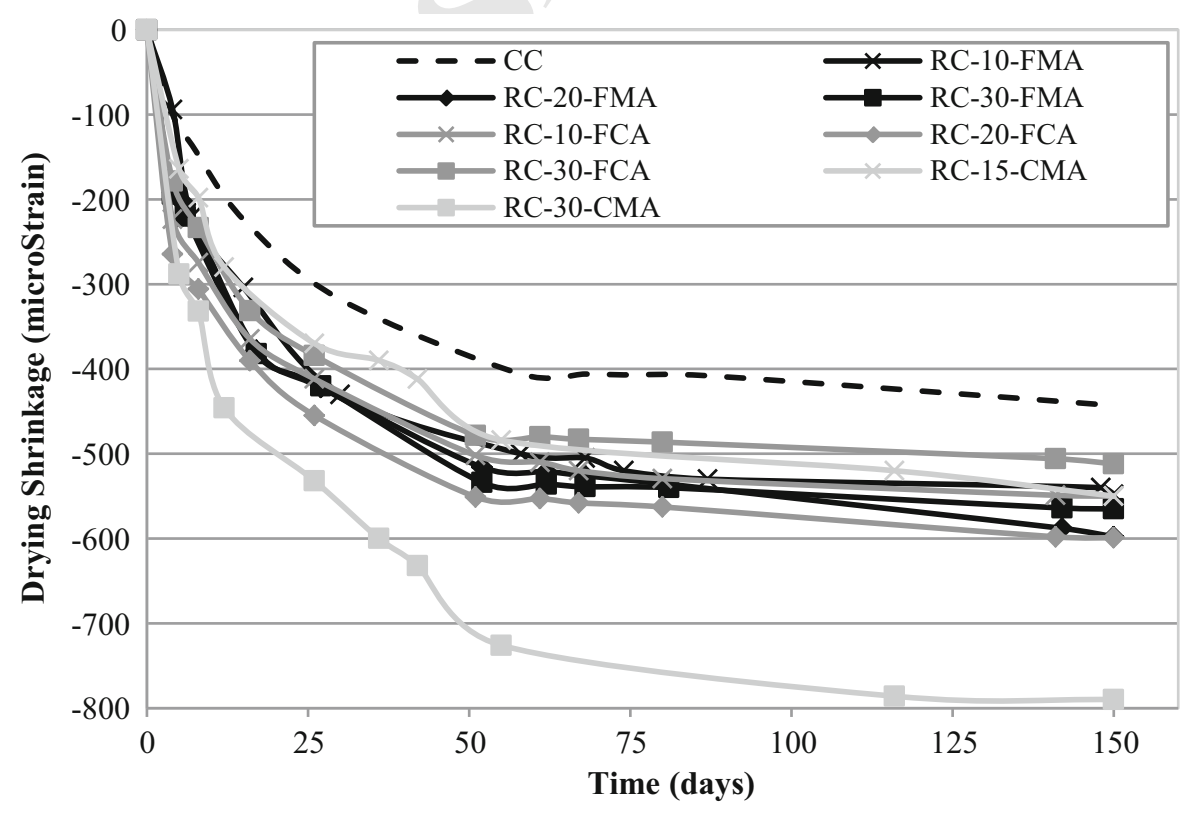

Fig. 8 Strain results registered by means of a dial gauge during the drying shrinkage test up to 150 days

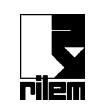

\begin{tabular}{|l|lll|}
\hline & Journal : Medium 11527 & Dispatch : 24-9-2018 & Pages : 21 \\
Article No. : $\mathbf{1 2 4 4}$ & $\square$ LE & $\square$ TYPESET \\
& MS Code : MAAS-D-17-01211 & $\checkmark \mathrm{CP}$ & $\searrow$ DISK \\
\hline
\end{tabular}




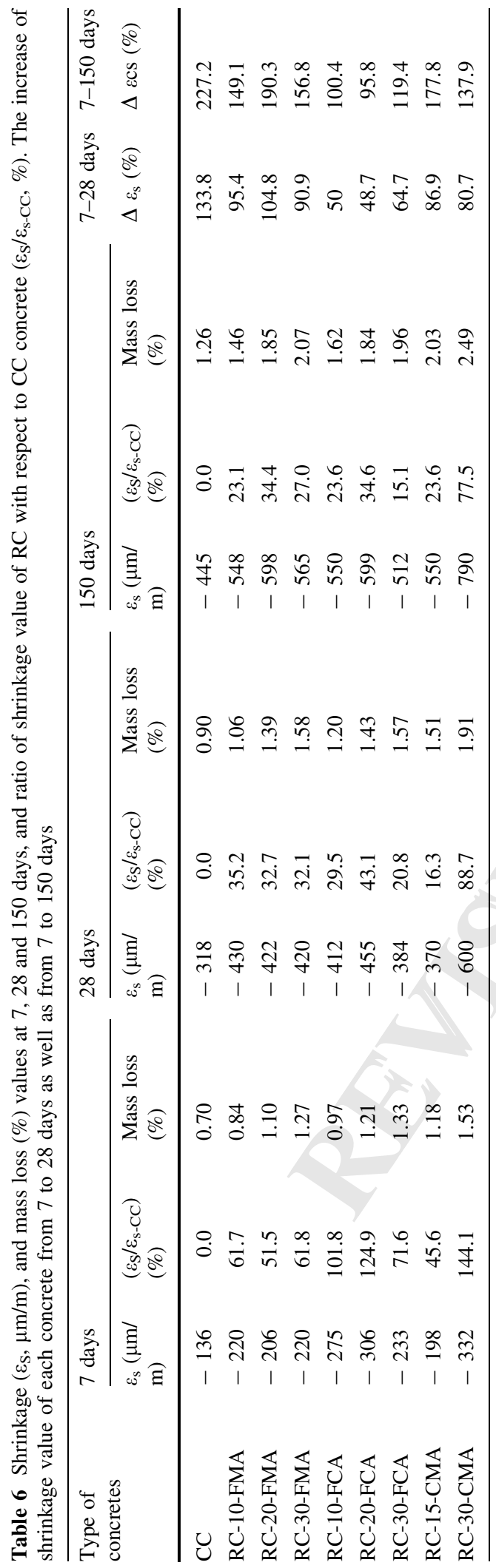

mixed aggregates led to the lower resistance to chloride-ion penetration $[14,18]$.

After 180 days, the resistance of the recycled aggregate concretes to chloride-ion penetration showed significantly higher improvements than that of the CC concrete, a fact observed in previous studies $[16,18]$. While the total charge passed of the FMA and CMA concretes were between 1160-1310 and 1285-1460 C, respectively, the CC concrete had a total charge passing of $1075 \mathrm{C}$. The $\mathrm{CC}$ concrete had a negligible reduction from 28 to 180 days of curing, whereas the FMA and CMA concretes achieved a reduction of up to 25 and $18 \%$, respectively. The concrete produced employing FCA aggregates achieved the highest increase of resistance to chloride penetration after 180 days of curing, this being the only concrete whose results were similar to those of other studies on lightweight aggregate concretes [24] as they reached the very low corrosion risk range. The resistance to chloride-ion penetration of the FCA concretes achieved a value of $830 \mathrm{C}$, causing a higher resistance than that of the $\mathrm{CC}$ concrete. In addition these concretes achieved the highest improvement of resistance with a reduction of up to $40 \%$ of passing charge from 28 to 180 days of curing.

The described long-term behaviour of the recycled aggregates is in all probability due to an adequate internal curing process. Similarly, as determined in the study of lightweight aggregate concretes [78], internal curing not only improves the cement hydration via an increase in the density of the outer layer of the recycled and lightweight aggregates, but also results in the cause of a high-quality interfacial zone between the recycled or lightweight aggregate and the mortar matrix [48], [49, 79]. These findings demonstrate that the porosity and water absorption from the recycled aggregates are not indicators of lower resistances to chloride-ion penetration.

\section{Conclusions}

The following conclusions can be drawn based on the 939 results presented above:

According to the use of ceramic aggregate in 941 concretes

- The concrete produced with up to $30 \%$ of fine ceramic aggregates reduced the absorption

\begin{tabular}{|l|lll|}
\hline & Journal : Medium 11527 & Dispatch : 24-9-2018 & Pages : 21 \\
Article No. : 1244 & $\square$ LE & $\square$ TYPESET \\
MS Code : MAAS-D-17-01211 & $\checkmark$ CP & $\checkmark$ DISK \\
\hline
\end{tabular}


Fig. 9 Chloride-ion penetration of concrete mixtures after 28 and 180 days; ASTM corrosion risk ranges indicated by doted lines

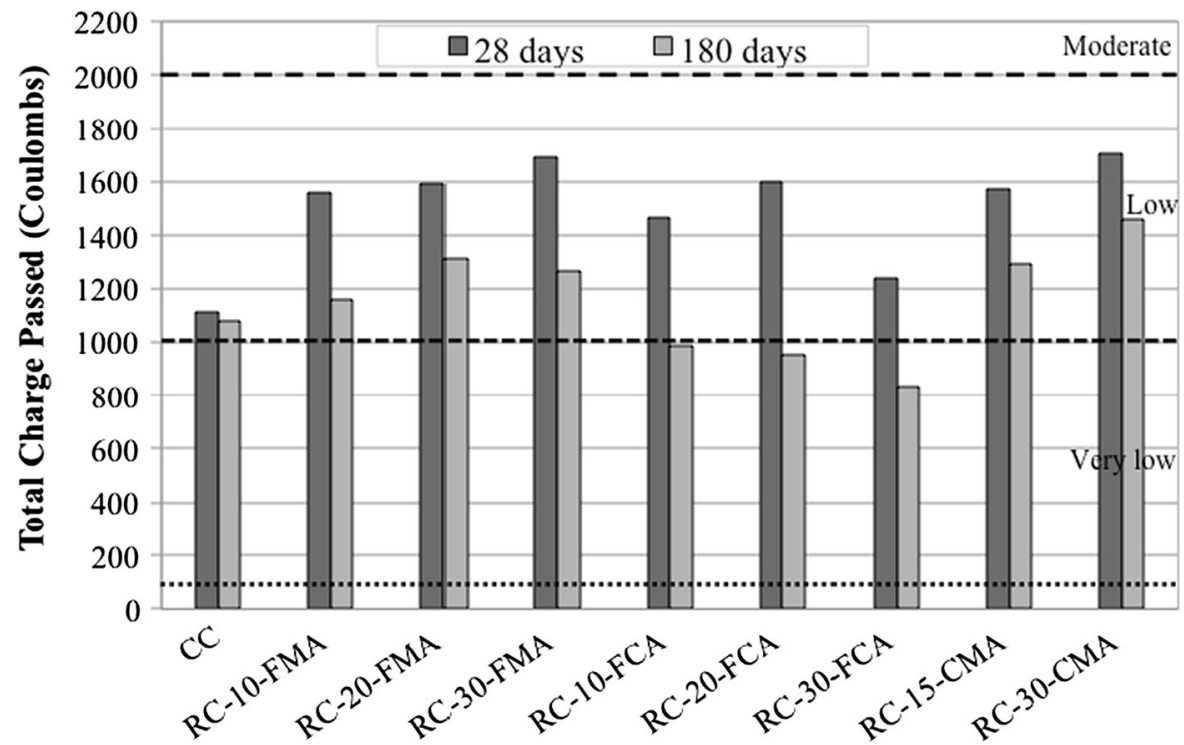

Type of concrete capacity as well as increasing the durability to chloride resistance and the compressive strength at 7 days, 28 days and 180 days with respect to those of CC concrete.

- The total plastic shrinkage of concretes produced with 10-30\% of ceramic aggregates was lower (up to $45 \%$ ) than that of CC concrete, this was due to water desorption capacity in the stages in which cement hydration was carried out.

- The autogenous shrinkage of those concrete was lower than that of CC concrete, being negligible in concretes produced employing 30\% of FCA (aggregates with $12 \%$ of water absorption capacity).

- Although the early drying shrinkage, at 7 days of testing, was up to $125 \%$ higher than that of CC concrete, at longer period of testing the recycled aggregate concretes were shown to have suffered lower shrinkage. The mass of water loss was always lower than the amount of water absorbed by the recycled aggregates (at concrete production instant), thus guaranteeing an adequate behaviour of those concretes.

According to the use of mixed recycled aggregate in concretes

- The use of recycled mixed aggregates up to 15 and $20 \%$ of CMA and FMA respectively, in substitution of natural aggregates proved to achieve similar or lower absorption capacity and volume accessible pores to those obtained by the conventional concrete. The concrete made with FMA achieved comparable strengths to those of conventional concrete, showing that it was far more influenced by the use of coarser aggregates.

- The plastic shrinkage of concretes produced with $30 \%$ of recycled mix aggregates with 17.8 and $16 \%$ of water absorption capacity achieved almost zero plastic shrinkage.

- The use of mixed recycled aggregates produced concretes with autogenous non-shrinking behaviour or also swelling up to 28 days. A very low percentage ( $10 \%$ or lower) of recycled aggregates or aggregates with low humidity grade was necessary in order to achieve zero strain value.

- While at 7 days the drying shrinkage of concretes produced with up to $30 \%$ of FMA and $15 \%$ of CMA was up to $60 \%$ higher than that of CC concrete, the long term drying shrinkage, from 7 tp 150 days was also lower than that of CC concretes, similar to concretes produced with FCA.

The use of $30 \%$ of fine ceramic aggregates (FCA, with $12 \%$ of absorption capacity) not only improved the shrinkage strain but also the mechanical and chloride ion resistance with respect to those of the CC concrete. In order to achieve the adequate properties in high performance concrete a low percentage of recycled mixed aggregates (RMA) (10-15\%), which had a high
973

974

975

976

977

978

979

980

981

982

983

984

985

986

987

988

989

990

991

992

993

994

995

996

997

998

999

1000

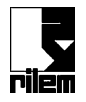

\begin{tabular}{|l|lll|}
\hline & Journal : Medium 11527 & Dispatch : 24-9-2018 & Pages : 21 \\
Article No. : $\mathbf{1 2 4 4}$ & $\square$ LE & $\square$ TYPESET \\
& MS Code : MAAS-D-17-01211 & $\cup_{\mathrm{CP}}$ & $\searrow$ DISK \\
\hline
\end{tabular}


water absorption capacity (16-17\%) must be employed.

\section{3}

1004

1005

1006

1007

1008

1009

1010

1011

Acknowledgements The authors wish to acknowledge the financial support of The Ministry of Economy and Competitiveness of the Government of Spain (MINECO) for providing funds for the INNPACT Project (IPT-2012-1093310000) and the European Regional Development Fund (FEDER).

\section{Compliance with ethical standards}

Conflict of interest The authors declare that they have no conflict of interest.

\section{References}

1. Sonawane TR, Pimplikar SS (2013) Use of recycled aggregate in concrete. Int J Eng Res Technol 2(1):1-9

2. Etxeberria M, Vázquez E, Marí A, Barra M (2007) Influence of amount of recycled coarse aggregates and production process on properties of recycled aggregate concrete. Cem Concr Res 37(5):735-742

3. Dhir RK, Paine KA, De Brito J, Etxeberria M, Ho NY, Poon CS, Tam VWY (2011) Use of recycled and secondary aggregates in concrete: engineering and environmental considerations. In: UKIERI concrete congress "new developments in concrete construction". pp 157-182

4. Poon CS, Shui ZH, Lam L, Fok H, Kou SC (2004) Influence of moisture states of natural and recycled aggregates on the slump and compressive strength of concrete. Cem Concr Res 34(1):31-36

5. De Brito J, Pereira AS, Correia JR (2005) Mechanical behaviour of non-structural concrete made with recycled ceramic aggregates. Cem Concr Compos 27(4):429-433

6. Deloitte (2017) Study on resource efficient use of mixed wastes, improving management of construction and demolition waste-final report. http://ec.europa.eu/environment/ waste/studies/pdf/CDW_Final_Report.pdf. Accessed Sept 2018

7. Directive 2008/98/EC European Parliament (2008) Directive 2008/98/EC on waste (waste framework directive). http://ec.europa.eu/environment/waste/framework/. Accessed Sept 2018

8. Ministry of Agriculture (2015) National framework plan for waste management (Plan Estatal Marco de Gestión de Residuos, PEMAR). https://www.mapama.gob.es/es/ calidad-y-evaluacion-ambiental/planes-y-estrategias/ pemaraprobado6noviembrecondae_tcm30-170428.pdf. Accessed Sept 2018

9. Alves AV, Vieira TF, De Brito J, Correia JR (2014) Mechanical properties of structural concrete with fine recycled ceramic aggregates. Constr Build Mater 64:103-113

10. Evangelista L, de Brito J (2007) Mechanical behaviour of concrete made with fine recycled concrete aggregates. Cem Concr Compos 29(5):397-401
11. Pedro D, De Brito J, Evangelista L (2014) Influence of the use of recycled concrete aggregates from different sources on structural concrete. Constr Build Mater 71:141-151

12. Juan-Valdés A, Rodríguez-Robles D, García-González J, Guerra-Romero MI, Morán-del Pozo JM (2018) Mechanical and microstructural characterization of non-structural precast concrete made with recycled mixed ceramic aggregates from construction and demolition wastes. J Clean Prod 180:482-493

13. Etxeberria M, Fernandez JM, Limeira J (2016) Secondary aggregates and seawater employment for sustainable concrete dyke blocks production: case study. Constr Build Mater 113:586-595

14. Kou SC, Poon CS, Wan H (2012) Properties of concrete prepared with low-grade recycled aggregates C \& D Waste. Constr Build Mater 36:881-889

15. Suzuki M, Seddik M, Meddah, Sato R (2009) Use of porous ceramic waste aggregates for internal curing of high-performance concrete. Cem Concr Res 39(5):373-381

16. Gonzalez-Corominas A, Etxeberria M (2014) Properties of high performance concrete made with recycled fine ceramic and coarse mixed aggregates. Constr Build Mater 68:618-626

17. Vejmelková E, Keppert M, Rovnaníková P, Ondráček M, Keršner Z, Černý R (2012) Properties of high performance concrete containing fine-ground ceramics as supplementary cementitious material. Cem Concr Compos 34(1):55-61

18. Etxeberria M, Vegas I (2014) Effect of fine ceramic recycled aggregate (RA) and mixed fine RA on hardened properties of concrete. Mag Concr Res 67:645-655

19. Silva RV, De Brito J, Dhir RK (2014) Properties and composition of recycled aggregates from construction and demolition waste suitable for concrete production. Constr Build Mater 65:201-217

20. Medina C, Sánchez De Rojas MI, Frías M (2013) Properties of recycled ceramic aggregate concretes: water resistance. Cem Concr Compos 40:21-29

21. Correia JR, De Brito J, Pereira AS (2006) Effects on concrete durability of using recycled ceramic aggregates. Mater Struct Constr 39(286): 169-177

22. Torkittikul P, Chaipanich A (2010) Utilization of ceramic waste as fine aggregate within Portland cement and fly ash concretes. Cem Concr Compos 32(6):440-449

23. Pacheco-Torgal F, Jalali S (2010) Reusing ceramic wastes in concrete. Constr Build Mater 24(5):832-838

24. Higashiyama H, Sappakittipakorn M, Sano M, Yagishita F (2012) Chloride ion penetration into mortar containing ceramic waste aggregate. Constr Build Mater 33:48-54

25. Higashiyama H, Yagishita F, Sano M, Takahashi O (2012) Compressive strength and resistance to chloride penetration of mortars using ceramic waste as fine aggregate. Constr Build Mater 26(1):96-101

26. Fujiwara $\mathrm{T}$ (2008) Effect of aggregate on drying shrinkage of concrete. J Adv Concr Technol 6(6):31-44

27. Zhutovsky S, Kovler K, Bentur A (2002) Efficiency of lightweight aggregates for internal curing of high strength concrete to eliminate autogenous shrinkage. Mater Struct 35(2):97-101

28. Bentz DP, Snyder KA (1999) Protected paste volume in concrete Extension to internal curing using saturated lightweight fine aggregate. Cem Concr Res 29(11):1863-1867
1053

1054

1055

1056

1057

1058

1059

1060

1061

1062

1063

1064

1065

1066

1067

1068

1069

1070

1071

1072

1073

1074

1075

1076

1077

1078

1079

1080

1081

1082

1083

1084

1085

1086

1087

1088

1089

1090

1091

1092

1093

1094

1095

1096

1097

1098

1099

1100

1101

1102

1103

1104

1105

1106

1107

1108

1109

1110

1111

1112

1113

\begin{tabular}{|l|lll|}
\hline & Journal : Medium 11527 & Dispatch : 24-9-2018 & Pages : 21 \\
Article No. : $\mathbf{1 2 4 4}$ & $\square$ LE & $\square$ TYPESET \\
& MS Code : MAAS-D-17-01211 & $\checkmark \mathrm{CP}$ & $\checkmark$ DISK \\
\hline
\end{tabular}


1114

1115

1116

1117

1118

1119

1120

1121

1122

1123

1124

1125

1126

1127

1128

1129

1130

1131

1132

1133

1134

1135

1136

1137

1138

1139

1140

1141

1142

1143

1144

1145

1146

1147

1148

1149

1150

1151

1152

1153

1154

1155

1156

1157

1158

1159

1160

1161

1162

1163

1164

1165

1166

1167

1168

1169

1170

1171

1172

1173

1174
29. Henkensiefken R, Bentz D, Nantung T, Weiss J (2009) Volume change and cracking in internally cured mixtures made with saturated lightweight aggregate under sealed and unsealed conditions. Cem Concr Compos 31(7):427-437

30. Shah SP, Weiss WJ (2000) High strength concrete: strength, permeability, and cracking. In: Proceedings of the PCI/ FHWA international symposium on high performance concrete. pp 331-340

31. Zhutovsky S, Kovler K (2012) Effect of internal curing on durability-related properties of high performance concrete. Cem Concr Res 42(1):20-26

32. Bentur A, Igarashi S, Kovler K (2001) Prevention of autogenous shrinkage in high-strength concrete by internal curing using wet lightweight aggregates. Cem Concr Res 31(11):1587-1591

33. Neville AM (1995) Properties of concrete, 4th edn. Longman, London

34. ACI Committee 209 (2005) Report on factors affecting shrinkage and creep of hardened concrete. American Concrete Institute

35. Sadati S, Khayat KH (2017) Restrained shrinkage cracking of recycled aggregate concrete. Mater Struct 50(4):206

36. Pedro D, de Brito J, Evangelista L (2017) Structural concrete with simultaneous incorporation of fine and coarse recycled concrete aggregates: mechanical, durability and long-term properties. Constr Build Mater 154:294-309

37. Medjigbodo S, Bendimerad AZ, Rozière E, Loukili A (2018) How do recycled concrete aggregates modify the shrinkage and self-healing properties? Cem Concr Compos 86:72-86

38. Dimitriou G, Savva P, Petrou MF (2018) Enhancing mechanical and durability properties of recycled aggregate concrete. Constr Build Mater 158:228-235

39. Bendimerad AZ, Rozière E, Loukili A (2016) Plastic shrinkage and cracking risk of recycled aggregates concrete. Constr Build Mater 121:733-745

40. Bui PT, Ogawa Y, Nakarai K, Kawai K, Sato R (2017) Internal curing of Class-F fly-ash concrete using high-volume roof-tile waste aggregate. Mater Struct Constr 50(4):1-12

41. Bravo M, de Brito J, Evangelista L, Pacheco J (2018) Durability and shrinkage of concrete with CDW as recycled aggregates: benefits from superplasticizer's incorporation and influence of CDW composition. Constr Build Mater 168:818-830

42. Silva RV, De Brito J, Dhir RK (2015) Prediction of the shrinkage behavior of recycled aggregate concrete: a review. Constr Build Mater 77:327-339

43. EHE-08 (2010) Code on structural concrete. Madrid, Spain: Centro de Publicaciones, Secretaría General Técnica, Ministerio de Fomento

44. Gonzalez-Corominas A, Etxeberria M (2016) Effects of using recycled concrete aggregates on the shrinkage of high performance concrete. Constr Build Mater 115:32-41

45. Bolomey J (1935) Granulation et prévision de la résistance probable des betons. Travaux 19(30):228-232

46. Fernández Cánovas M (2013) Concrete, 10th edn. Garceta, Madrid (in Spanish)

47. Evangelista L, De Brito J (2010) Durability performance of concrete made with fine recycled concrete aggregates. Cem Concr Compos 32(1):9-14
48. Etxeberria M, Vázquez E, Marí AR (2006) Microstructure analysis of hardened recycled aggregate concrete. Mag Concr Res 58:683-690

49. Poon CS, Shui ZH, Lam L (2004) Effect of microstructure of ITZ on compressive strength of concrete prepared with recycled aggregates. Constr Build Mater 18(6):461-468

50. Saliba J, Rozière E, Grondin F, Loukili A (2011) Influence of shrinkage-reducing admixtures on plastic and long-term shrinkage. Cem Concr Compos 33(2):209-217

51. JCI Committee Report (1999) Technical committee on autogenous shrinkage of Concrete, "Autogenous shrinkage of concrete". FN \& Spon, Hiroshima

52. Medina C, Zhu W, Howind T, Sánchez de Rojas MI, Frías M (2014) Influence of mixed recycled aggregate on the physical: mechanical properties of recycled concrete. J Clean Prod 68:216-225

53. Khatib JM (2005) Properties of concrete incorporating fine recycled aggregate. Cem Concr Res 35(4):763-769

54. Elsharief A, Cohen MD, Olek J (2005) Influence of lightweight aggregate on the microstructure and durability of mortar. Cem Concr Res 35(7):1368-1376

55. Etxeberria IVM, Gonzalez-Corominas A (2013) Application of low-grade recycled aggregates for non-structural concrete production in Barcelona city. In: International conference on sustainable construction materials and technologies

56. López V, Llamas B, Juan A, Morán JM, Guerra I (2007) Eco-efficient concretes: impact of the use of white ceramic powder on the mechanical properties of concrete. Biosyst Eng 96(4):559-564

57. Golias M, Castro J, Weiss J (2012) The influence of the initial moisture content of lightweight aggregate on internal curing. Constr Build Mater 35:52-62

58. Ajdukiewicz A, Kliszczewicz A (2002) Influence of recycled aggregates on mechanical properties of HS/HPC. Cem Concr Compos 24(2):269-279

59. ACI Committee 363 (1997) State of the art report on highstrength concrete. Farmington Hills

60. Corinaldesi V, Moriconi G (2015) Use of synthetic fibers in self-compacting lightweight aggregate concretes. J Build Eng 4:247-254

61. Martínez-Lage I, Martínez-Abella F, Vázquez-Herrero C, Pérez-Ordóñez JL (2012) Properties of plain concrete made with mixed recycled coarse aggregate. Constr Build Mater 37:171-176

62. Mora-Ruacho J, Gettu R, Aguado A (2009) Influence of shrinkage-reducing admixtures on the reduction of plastic shrinkage cracking in concrete. Cem Concr Res 39(3):141-146

63. Castro J, Keiser L, Golias M, Weiss J (2011) Absorption and desorption properties of fine lightweight aggregate for application to internally cured concrete mixtures. Cem Concr Compos 33(10):1001-1008

64. Pepe M, Koenders EAB, Faella C, Martinelli E (2014) Structural concrete made with recycled aggregates: hydration process and compressive strength models. Mech Res Commun 58:139-145

65. Baghabra Al-Amoudi OS, Maslehuddin M, Abiola TO (2004) Effect of type and dosage of silica fume on plastic shrinkage in concrete exposed to hot weather. Constr Build Mater 18(10):737-743

\begin{tabular}{|l|lll|}
\hline & Journal : Medium 11527 & Dispatch : 24-9-2018 & Pages : 21 \\
Article No. : $\mathbf{1 2 4 4}$ & $\square$ LE & $\square$ TYPESET \\
MS Code : MAAS-D-17-01211 & $\checkmark \mathrm{CP}$ & $\checkmark$ DISK \\
\hline
\end{tabular}


1236

1237

1238

1239

1240

1241

1242

1243

1244

1245

1246

1247

1248

1249

1250

1251

1252

1253

1254

1255

1256

1257

1258

1259
66. Wyrzykowski M, Trtik P, Münch B, Weiss J, Vontobel P, Lura P (2015) Plastic shrinkage of mortars with shrinkage reducing admixture and lightweight aggregates studied by neutron tomography. Cem Concr Res 73:238-245

67. Etxeberria M, Gonzalez-Corominas A, Pardo P (2016) Influence of seawater and blast furnace cement employment on recycled aggregate concretes' properties. Constr Build Mater 115:496-505

68. Meddah MS, Sato R (2010) Effect of curing methods on autogenous shrinkage and self-induced stress of high-performance concrete. ACI Mater J 107(1):65-74

69. Hewlett P (2004) Lea's chemistry of cement and concrete, 4th edn. Butterworth-Heineman, Oxford

70. Meddah MS, Suzuki M, Sato R (2011) Influence of a combination of expansive and shrinkage-reducing admixture on autogenous deformation and self-stress of silica fume high-performance concrete. Constr Build Mater 25(1):239-250

71. Souche JC et al (2017) Early age behaviour of recycled concrete aggregates under normal and severe drying conditions. J Build Eng 13(January):244-253

72. Kou S, Poon C (2015) Effect of the quality of parent concrete on the properties of high performance recycled aggregate concrete. Constr Build Mater 77:501-508
73. Kou S-C, Zhan B, Poon C-S (2014) Use of a CO2 curing step to improve the properties of concrete prepared with recycled aggregates. Cem Concr Compos 45:22-28

74. Silva RV, De Brito J, Neves R, Dhir R (2015) Prediction of chloride ion penetration of recycled aggregate concrete. Mater Res 18(2):427-440

75. Gómez-Soberón JM (2009) Shrinkage of concrete with replacement of aggregate with recycled concrete aggregate. ACI Spec Publ 209:475-496

76. Jin L, Du X, Ma G (2012) Macroscopic effective moduli and tensile strength of saturated concrete. Cem Concr Res 42(12):1590-1600

77. Gonzalez-Corominas A, Etxeberria M (2014) Experimental analysis of properties of high performance recycled aggregate concrete. Constr Build Mater 52:227-235

78. Chia KS, Zhang M-H (2002) Water permeability and chloride penetrability of high-strength lightweight aggregate concrete. Cem Concr Res 32:639-645

79. Zhang MH, Gjørv OE (1990) Microstructure of the interfacial zone between lightweight aggregate and cement paste. Cem Concr Res 20(4):610-618

\begin{tabular}{|l|lll|}
\hline Journal : Medium 11527 & Dispatch : 24-9-2018 & Pages : 21 \\
Article No. : $\mathbf{1 2 4 4}$ & $\square$ LE & $\square$ TYPESET \\
MS Code : MAAS-D-17-01211 & $\bigcup_{\mathrm{CP}}$ & $\checkmark$ DISK \\
\hline
\end{tabular}

